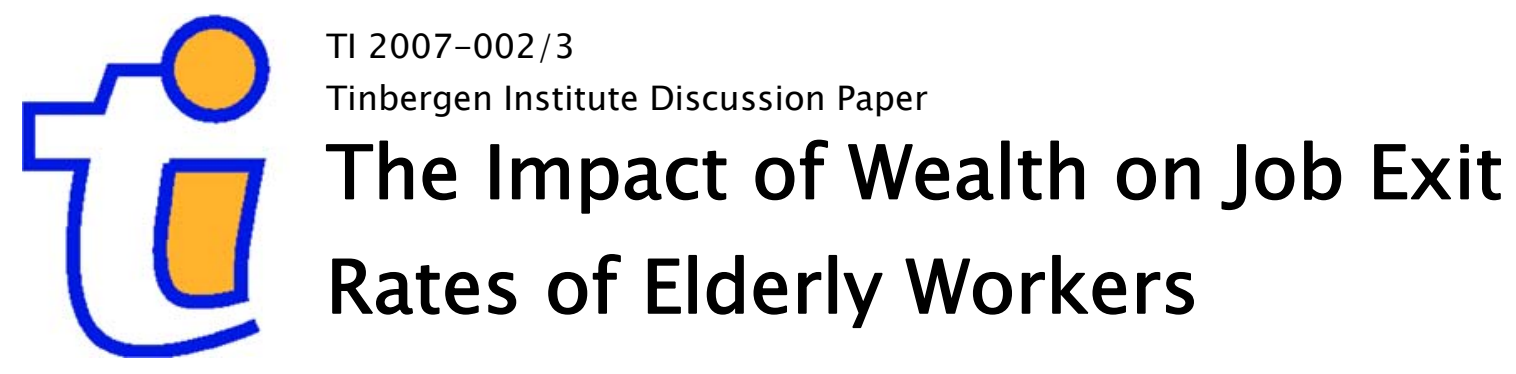

Hans Bloemen

Vrije Universiteit Amsterdam, and Tinbergen Institute. 


\section{Tinbergen Institute}

The Tinbergen Institute is the institute for economic research of the Erasmus Universiteit Rotterdam, Universiteit van Amsterdam, and Vrije Universiteit Amsterdam.

Tinbergen Institute Amsterdam

Roetersstraat 31

1018 WB Amsterdam

The Netherlands

Tel.: $\quad+31(0) 205513500$

Fax: $\quad+31(0) 205513555$

Tinbergen Institute Rotterdam

Burg. Oudlaan 50

3062 PA Rotterdam

The Netherlands

Tel.: $\quad+31(0) 104088900$

Fax: $\quad+31(0) 104089031$

Most TI discussion papers can be downloaded at http:/ /www.tinbergen.nl. 


\title{
The Impact of Wealth on Job Exit Rates of Elderly Workers
}

\author{
Hans G. Bloemen ${ }^{1,2,3}$ \\ Department of Economics \\ Free University Amsterdam \\ De Boelelaan 1105 \\ 1081 HV Amsterdam \\ The Netherlands
}

This version January 2007

Keywords: Retirement, Life Cycle Models and Saving

JEL code: J26, D91

\begin{abstract}
Theoretical models predict a positive impact of the level of individual wealth on the job exit probability. Empirically this prediction is most likely to be relevant for elderly workers who have accumulated wealth throughout their working life and have a short residual working life. In the Netherlands, as in other European countries, there is a policy debate about the introduction of more individual freedom of choice in pension schemes. The individual level of wealth will become an increasingly important factor in the retirement decision. Therefore it is relevant to know whether workers with a different financial situation make different job exit decisions, given other factors. Empirical analysis of job exit behaviour of elderly workers so far has concentrated on properties of the pension system and health status. For a sample of elderly male workers in the Netherlands in the period 1995 through 2001, we analyse the impact of wealth, savings, and debt position on job exit rates. We find evidence for a positive effect of wealth on the probability to retire (early).
\end{abstract}

\footnotetext{
${ }^{1}$ We are greatly indebted to Statistics Netherlands for providing the data. Earlier versions of this paper were presented at the Netspar Pension Day February 2006, The CPB Netherlands Bureau for Economic Policy Analysis, and the Netspar Workshop Microeconomics of Aging in Europe. We thank Arthur van Soest, Daniel van Vuuren, Matthew Wakefield, and other seminar participants for their comments. All errors are mine.

2 email: hbloemen@feweb.vu.nl, phone: +31 20 5986037, fax: +31 205986005

3 Tinbergen Institute, Netspar, IZA.
} 


\section{Introduction}

Labour market participation rates in the Netherlands typically tend to decrease once workers have passed the age of 50. Empirical analysis of the outflow of elderly workers out of the labor market has focused on the financial incentives created by social insurance and early retirement systems. ${ }^{4}$ Structural empirical models of retirement behavior, as, for instance, the model by Stock and Wise (1990), also concentrate on the properties of the retirement system on the job exit decision.

So far evidence on the impact of the private level of wealth on the decision to retire is scarce. It becomes increasingly interesting to gain insight in the empirical impact of the financial situation on the decision to exit the labour market as recent policy measures in the Netherlands aim at more individual flexibility in the choice to retire from the labour market.

Theoretical models on savings and labor market transitions by Blundell, Magnac and Meghir (1997), and Danforth (1979) incorporate the role of wealth on the flows out of unemployment, while the first study also addresses the relation between wealth and the flow out of employment. It predicts that workers with a higher level of wealth will have a higher probability of job exit, given other factors. This result holds for any worker, and is not specific to the retirement decision of elderly workers. The model also predicts a negative relation between the level of wealth and the transition probability from unemployment to employment, and the influence of wealth on the transitions in the different directions come from the same source: therefore evidence of a negative impact of wealth on the flow out of unemployment is indirect evidence of a positive impact of wealth on the flow out of employment, provided that the model structure holds. Woolley (2004) explicitly models the retirement decision, along with an intertemporal wealth accumulation relation, and the model also predicts that a higher level of wealth increases the probability of retirement.

Empirical evidence by Stancanelli (1999), Bloemen and Stancanelli (2001), and Bloemen (2002) shows that there is an impact of wealth on the flow from unemployment

\footnotetext{
${ }^{4}$ See Kapteyn and De Vos (1998), and Lindeboom (1998) for studies for the Netherlands.
} 
into employment. However, there is little direct evidence on the impact of savings on the exit out of the labor market of elderly workers. Bloemen (2002) measures the impact of wealth on the transition from employment to nonemployment for male workers in the age range of 20 to 64 and finds a negative impact of wealth on the transition out of employment, which is opposite to the effect predicted by theory. The possible explanation for the opposite effect that is provided is that wealth may serve as a proxy for unobserved heterogeneity: someone with a high level of wealth may have favourable charactertistics that makes him more likely to stay on the job during working life. To address this issue Bloemen (2002) specifies a joint model of wealth and labour market transitions that includes unobserved heterogeneity, by allowing for random effects, initial conditions, and endogeneity of wealth. The estimates of the model specification show a smaller positive effect of wealth on the stay-on probability. A critisicm on this joint dynamic random effects model for wealth and labour market transition is that economic theory hardly provides suitable (non-parametric) exclusion restrictions for identification. For this reason, in this paper we aim to control for observed heterogeneity as much as possible using a rich set of regressors.

Studying the impact of wealth on the job exit probability is likely to be more relevant if we focus on the job exit behaviour of elderly workers. Someone aged, say, 30 still is many years away from the usual retirement age of 65 , and there will be few workers of that age that have already accumulated a sufficient amount of wealth to finance the daily necessities for 35 years. Many job exit transitions at earlier age in working life are lay-offs rather than quits. Blundell et al. (1997) model the staying-on probability as the product of a job offer probability and a job acceptance decision. Wealth thus enters the transition probability by the job acceptance decision but if job exit is dominated by quits, it is hard to empirically identify the impact of wealth on job exit, escpecially if unobserved heterogeneity in the wealth level is correlated with lay-offs. Bloemen (2002) only analyses job exit, and not the reason for the job exit. Moreover, a job quit may induce the loss of pension rights. If workers with a high level of wealth tend to have more favorable jobs with better pension arrangements, it will be unlikely that we will find a positive impact of wealth on the job exit rate. 
In this paper we estimate the empirical impact of wealth on the job exit behaviour of elderly workers. For this purpose we use a subsample of the data from the Socio Economic Panel, collected by Statistics Netherlands. We use a sample of male workers in the age range of 48 to 64 . We consider exit out of employment to various exit states. There are several factors that complicate the measurement of the impact of wealth on exit out of the labor market. Search theory emphasizes the impact of the income on the job, frictions on the labor market and the possibility of involuntary exit. Moreover, eligibility conditions for benefits in the state of inactivity may be a dominant factor in determining the job exit decision. The survey contains information on reasons for job exit and we will exploit this information in the empirical analysis. We use a multinomial choice framework in which the individual may exit by different exit routes, or may stay employed. We use a reduced form regression model, as our purpose is to try and measure whether wealth has an impact on job exit rates, without a priori imposing such a relationship. To isolate the impact of wealth from other factors we use a rich set of regressors. We include, among other, information on fixed term contracts, participation in employee or individual pension schemes, and the wage of the current job. We will use different measures for wealth, savings, and debt position.

In section 2 we present a simplified economic model that serves as a background to motivate our empirical specification. The model shows which factors are relevant in taking the job exit decision, and generates predictions on both the impact of wealth and the impact of the wage income on the job exit decision. Section 3 provides a brief description of the pension system in the Netherlands. In section 4 we present the data. Section 5 contains the empirical analysis. We present the empirical model, the estimation results, and elasticities of job exit probabilities with respect to wealth. Section 6 concludes.

\section{Theoretical background}

In this section we present a simple economic model that includes both the savings decision and the decision to retire. The purpose of this section is to make explicit which 
factors influence the decision to exit from employment, and serves as a guideline for the specification of our empirical model.

In our model an individual makes choices in three subsequent periods. The three periods can be interpreted as three phases in life. In the first period the individual is employed, earns an income, accumulates pension wealth, spends income on consumption, and saves or borrows. In the second period, the individual can choose to stop or to continue working. If the individual continues working, he continues accumulating pension wealth, and continues receiving wage income. If the individual stops working he receives a benefit income, that may depend on past earnings (the wage income in period 1). Typically, the benefit income will be lower than the earnings. In the final period, there is mandatory retirement, and the individual does not work. Needless to say, the model can be further refined. For instance, in the middle period the individual may choose among different states of inactivity associated with different eligibility rules and different benefit levels, but for the purpose of showing the mechanisms by which private wealth enters the decision we stick to the three period framework.

Individual preferences are expressed by an intratemporal utility function $U\left(C_{\tau}, d_{\tau}\right)$ defined over consumption $C_{\tau}$ and labour market state $d_{\tau}\left(d_{\tau}=1\right.$ if employed, $d_{\tau}=0$ if inactive) in periode $\tau$. There is a constant rate of time preference $\rho$, and we label the three periods 0,1 , and 2 . Given the above assumptions $d_{0}=1$ and $d_{2}=0$. Net wealth at the beginning of period $\tau$ is indicated by $A_{\tau}$. The interest rate is constant and equal to $r$. Income in period $\tau$ is indicated by $y_{\tau}$. Thus, we have the following intratemporal budget constraint:

$$
C_{\tau}=y_{\tau}+r A_{\tau}+A_{\tau}-A_{\tau+1}, \tau=0,1,2, \text { with } A_{3}=0
$$

The objective of the individual is the maximization of the expected intertemporal utility $^{5}$

$$
E \sum_{\tau=0}^{2}\left(\frac{1}{1+\rho}\right)^{\tau} U\left(C_{\tau}, d_{\tau}\right)
$$

For income in period 1 we have that $y_{1}=Y\left(d_{1}, y_{0}\right)$, which indicates that the income depends on the labour market state chosen and that the level of earnings in period 0

\footnotetext{
5 Uncertainty may arise due to uncertainty in future income.
} 
affects the level of income, for instance, because it determines the benefit level. Similary, we denote income in period 2 as $y_{2}=b\left(y_{1}, d_{1}\right)=b\left(Y\left(d_{1}, y_{0}\right), d_{1}\right)$. Thus, the labour market state in the previous period determines the final pension benefit, as do the earnings levels in the previous periods. We make the following assumptions about the income processes:

$$
Y\left(1, y_{0}\right)>Y\left(0, y_{0}\right), \frac{\partial Y\left(d_{1}, y_{0}\right)}{\partial y_{0}}>0, \frac{\partial b\left(y_{1}, d_{1}\right)}{\partial y_{1}}>0, b\left(y_{1}, 1\right)>b\left(y_{1}, 0\right)
$$

The first inequality in (3) says that the income of someone working in period 1 is higher than the income of someone retired in period 1, so there is a financial payoff to continue working. The second inequality says that someone with higher earnings in working life (period 0) will also have higher income in period 1, irrespective of the labour market state in period 1 . The third and fourth inequality state that a higher income in period 1 and employment status in period 1 both imply a higher pension benefit in period 2 . Together with inequality 1 , this indicates that there is an additional incentive to continue working in period 1 , as not only period 1 income will be higher, but also the eventual pension benefit. Note that the loss of pension rights can be incorporated in the notation. Loss of pension rights or ineligibility to (early) retirement benefits can be denoted as $b\left(y_{1}, 0\right) \equiv 0$ or $Y\left(0, y_{0}\right) \equiv 0$.

The model outlined contains both the consumption/savings decision, and the decision to retire early. In the absence of liquidity constraints, the Euler equation for consumption holds and the model implies consumption smoothing:

$$
\frac{\partial U\left(C_{\tau}, d_{\tau}\right)}{\partial C_{\tau}}=\frac{1+r}{1+\rho} E_{\tau} \frac{\partial U\left(C_{\tau+1}, d_{\tau+1}\right)}{\partial C_{\tau+1}}, \tau=0,1,2
$$

The assumptions (3) imply that income decreases on retirement so consumption can be smoothed by decumulating savings. ${ }^{6}$

In period 1 the decision to retire early is taken. Let $V_{1}\left(A_{1}, y_{0} ; d_{1}\right)$ indicate the value function in period 1 , conditional on choosing labour market state $d_{1}$, and let $C_{\tau}^{d_{1}}, \tau=1,2$ and $A_{2}^{d_{1}}$ denote optimal choices conditional on $d_{1}$ : they satisfy the Euler equation (4).

\footnotetext{
${ }^{6}$ In the empirical literature on consumption upon retirement evidence shows that upon retirement the retired do not always smooth consumption (see, for instance, Hamermesh (1984) and Alessie, Lusardi, and Kapteyn (1999)).
} 
Then we write the value function as

$$
V_{1}\left(A_{1}, y_{0} ; d_{1}\right)=U\left(C_{1}^{d_{1}}, d_{1}\right)+\frac{1}{1+\rho} E_{1} U\left(C_{2}^{d_{1}}, 0\right)
$$

with

$$
\begin{aligned}
& C_{1}^{d_{1}}=Y\left(d_{1}, y_{0}\right)+(1+r) A_{1}-A_{2}^{d_{1}} \\
& C_{2}^{d_{1}}=b\left(Y\left(d_{1}, y_{0}\right), d_{1}\right)+(1+r) A_{2}^{d_{1}}
\end{aligned}
$$

The decision to retire early can be characterized as

$$
\begin{aligned}
& \text { If } V_{1}\left(A_{1}, y_{0} ; 0\right)-V_{1}\left(A_{1}, y_{0} ; 1\right)>0: \text { stop working } \\
& \text { If } V_{1}\left(A_{1}, y_{0} ; 0\right)-V_{1}\left(A_{1}, y_{0} ; 1\right) \leq 0: \text { continue working }
\end{aligned}
$$

To evaluate the impact of the level of wealth $A_{1}$ on the decision to retire early, we consider

$$
\frac{\partial V_{1}\left(A_{1}, y_{0} ; 0\right)}{\partial A_{1}}-\frac{\partial V_{1}\left(A_{1}, y_{0} ; 1\right)}{\partial A_{1}}=\frac{\partial U\left(C_{1}^{0}, 0\right)}{\partial C_{1}}-\frac{\partial U\left(C_{1}^{1}, 1\right)}{\partial C_{1}}
$$

Although the presentation of the model in this section is somewhat different, the result by Blundell, Magnac, and Meghir (1997) can be applied to (8): if the value function in (5) is concave in $A_{1}$ and if

$$
\frac{\partial^{2} U\left(C_{\tau}, d_{\tau}\right)}{\partial C_{\tau} \partial d_{\tau}}<0
$$

then expression (8) is positive, indicating that the option to leave the job becomes more attractive relative to the option to stay on the job the higher is the level of wealth $A_{1}$. Thus, the probability to exit the job will be higher, the higher is the level of wealth. This result (i.e. the qualitative result that the impact of wealth on job exit is positive) does not depend on the shape of the income relations $Y\left(d_{1}, y_{0}\right)$ and $b\left(y_{1}, d_{1}\right)$, except for the fact that replacement rates are assumed to be smaller than 1: income is smaller in the state of inactivity. This is because the level of wealth does not influence the level of benefits in the state on inactivity. However, the quantitative impact of wealth on the job exit will be effected by the shape of $Y\left(d_{1}, y_{0}\right)$ and $b\left(y_{1}, d_{1}\right)$. For instance, the higher are replacement rates, the closer will be $C_{1}^{0}$ and $C_{1}^{1}$ in (8) and the impact of wealth on the job exit decision may become smaller.

\footnotetext{
7 Note that (9) implies that the marginal utility of consumption at a given consumption level is higher if the individual has full leisure compared to the situation in which the individual is working.
} 
Thus, under some regularity conditions, the model implies that the decision to exit the job will be positively influenced by the level of wealth, given everything else. Some comments are in order. The model formulated so far concentrates on job exit as a decision by the worker: wealth enters the job exit rate because it affects the choice of the worker. However, workers not always exit jobs by choice. Demand side factors may force them to leave the job. It is straightforward to extend the model with an exogenous layoff rate, ${ }^{8}$ in which case the job exit rate consists of the layoff rate and the choice probability to exit the job. This weakens the relation between the job exit rate and the level of wealth, but the theory does still predict a positive relationship. For an empirical analysis it is desirable to be able to observe the distinction between a forced job exit and a job exit by choice. On the other hand, in the discussion about job exit routes for elderly workers in the Netherlands, the unemployment benefit system and the disability insurance system are often mentioned as financially attractive exit routes for workers who are not (yet) eligible for a pension. Workers need to satisfy the eligibility rules of these systems, but a choice element by the worker may not be entirely absent.

Another factor that complicates the empirical measurement of the level of wealth on job exit are the eligibility rules and incentives of the early retirement system. Kapteyn and De Vos (1998) show that the early retirement system provides strong incentives to exit the labour force as soon as the early retirement age has been reached. If the rules of the early retirement system dominate the choice to retire early, the role of other factors may be limited.

Due to these considerations, we do not limit our analysis to one specific exit route. We will analyse the impact of wealth on the job exit rates of employed males in the entire age range of 48 through 64, and we allow for any reason of job exit (except death, in which case sample attrition occurs). The data allow us to make a rough distinction between various reasons of job exit and we will exploit this distinction in our empirical analysis.

The model outlined so far also enables us to analyse the effect of labour income $y_{0}$, that enters the value function (5), on the decision to exit from work. Without a life

\footnotetext{
8 See Blundell et al. (1997).
} 
cycle model framework, it is tempting to think that a higher labour income $y_{0}$ makes it more attractive to stay on the job. ${ }^{9}$ However, a higher labour income increases the entire life cycle budget, and, under an assumption like (9), a higher life cycle budget will make it more attractive to consume full leisure and to stop working. But the assumed impact (3) of the labour income and the labour market state on the early retirement benefits $Y\left(d_{1}, y_{0}\right)$ and the pension benefits $b\left(y_{1}, d_{1}\right)$ determine the negative incentives to stop working of a higher labour income during working life. To be more specific, we evaluate the impact of labour income $y_{0}$ on the job exit decision, determined by $V_{1}\left(A_{1}, y_{0} ; 0\right)-V_{1}\left(A_{1}, y_{0} ; 1\right)$ :

$$
\begin{gathered}
\frac{\partial V_{1}\left(A_{1}, y_{0} ; 0\right)}{\partial y_{0}}-\frac{\partial V_{1}\left(A_{1}, y_{0} ; 1\right)}{\partial y_{0}}=\frac{\partial U\left(C_{1}^{0}, 0\right)}{\partial C_{1}} \frac{\partial Y\left(0, y_{0}\right)}{\partial y_{0}}-\frac{\partial U\left(C_{1}^{1}, 1\right)}{\partial C_{1}} \frac{\partial Y\left(1, y_{0}\right)}{\partial y_{0}}+ \\
+\frac{1}{1+\rho} E_{1}\left[\frac{\partial U\left(C_{2}^{0}, 0\right)}{\partial C_{2}} \frac{\partial b\left(Y\left(0, y_{0}\right), 0\right)}{\partial y_{0}}-\frac{\partial U\left(C_{2}^{1}, 0\right)}{\partial C_{2}} \frac{\partial b\left(Y\left(1, y_{0}\right), 1\right)}{\partial y_{0}}\right]
\end{gathered}
$$

Making use of the Euler equation (4), together with the assumption that the retirement benefit (system) is completely known in period 1, we can rewrite (10) as

$$
\begin{aligned}
\frac{\partial V_{1}\left(A_{1}, y_{0} ; 0\right)}{\partial y_{0}}- & \frac{\partial V_{1}\left(A_{1}, y_{0} ; 1\right)}{\partial y_{0}}=\frac{\partial U\left(C_{1}^{0}, 0\right)}{\partial C_{1}}\left[\frac{\partial Y\left(0, y_{0}\right)}{\partial y_{0}}+\frac{1}{1+r} \frac{\partial b\left(Y\left(0, y_{0}\right), 0\right)}{\partial y_{0}}\right] \\
& -\frac{\partial U\left(C_{1}^{1}, 1\right)}{\partial C_{1}}\left[\frac{\partial Y\left(1, y_{0}\right)}{\partial y_{0}}+\frac{1}{1+r} \frac{\partial b\left(Y\left(1, y_{0}\right), 1\right)}{\partial y_{0}}\right]
\end{aligned}
$$

The impact (11) of the wage on the job exit decision has something in common with the impact (8) of wealth on the job exit decision: it contains the difference in the marginal utility of consumption in period 1 in the two labour market states. But the impact (11) of the wage adds some factors to this difference. We know that under the given assumptions (8) is positive. The questions is: (how) do the factors added in (11) change the sign? First, we know that if the replacement ratio of the early retirement system is smaller than 1, we have

$$
\frac{\partial Y\left(0, y_{0}\right)}{\partial y_{0}}<\frac{\partial Y\left(1, y_{0}\right)}{\partial y_{0}}
$$

\footnotetext{
${ }^{9}$ For instance, in job search models with on-the-job search, the reservation wage of the present job is determined by the current wage and consequently it is less likely that someone decides to exit from that job the higher is the wage.
} 
and if early retirement decreases the pension benefit in period 2 due to, say smaller premium payments in period 1 , we have

$$
\frac{\partial b\left(Y\left(0, y_{0}\right), 0\right)}{\partial y_{0}}<\frac{\partial b\left(Y\left(1, y_{0}\right), 1\right)}{\partial y_{0}}
$$

Thus, (12) and (13) imply that (11) is smaller than (8), and may even become negative if replacement rates are small enough. Summarizing, we can say that there are two opposing effects of the wage on the job exit decision. The first effect is the life cycle income effect. This effect is comparable to the effect of wealth on the job exit decision (8) and implies a positive influence of the wage income $y_{0}$ on the probability of job exit. There is a second, opposing, influence on the job exit probability that will make the total effect smaller or even negative, depending on the size of the replacement rates of early retirement and on the influence of the early retirement decision on final pension benefits: the smaller are the replacement rates, the smaller will become the impact of the wage income on the job exit rate. If the early retirement decision has no consequences for the pension benefits in period 2 and/or if the replacement rate of the early retirement system is large, which is typically the case in the Netherlands, the opposing negative effect will be small and a positive effect of the wage on the decision to retire early may prevail.

\section{Pension system and exit routes in the Netherlands}

We give a brief overview of the pension system in the Netherlands. Someone retired may receive pension income from different resources. There is the state pension, ${ }^{10}$ comparable to Social Security in the United States, and there are employer provided pension schemes. The early retirement system is also an employer provided facility.

Every individual in the Netherlands who has reached the age of 65 receives the state pension, irrespective of labour market state, other sources of pension income, or private wealth. Single individuals receive 70 percent of the minimum wage. A couple receives 100 percent of the minimum wage. There is an addition for households with dependent children.

\footnotetext{
10 The "AOW".
} 
Employed individuals participate in an employer provided pension scheme. Premium contribution is mandatory so in that sense it resembles a public pension system. However, rules of the pension system may vary from sector to sector. But there are many similarities between the sector. The pension schemes are of the defined benefit type, and pension benefit incomes depend on the final wage. The usual age of retirement is 65 . Financing is mostly fully funded.

Early retirement benefits are also employer provided and sector specific. Differences between sectors show up in the age of eligibility and the replacement rate. In most sectors the age of eligibility is in the range of 57 through 62 , with the age of 60 as the most common age. Replacement rates are between 70 and 85 percent of final earnings, with a concentration around 80 percent. Common to all sectors is that for eligibility job tenure has to be 10 years or more and that full withdrawal from the labour market is required..$^{11}$

Kapteyn and De Vos (1998) notice that the early retirement pension system is not the only destination of elderly workers that exit the job. The exit rate into disability rises with age. Other workers enter the unemployment insurance system and once unemployed, reemployment rates of eldery workers are very low. Kapteyn and De Vos (1998) suggest that there may be a link between exit into these states and the financial incentives provided by the corresponding benefit systems. The replacement rate of both the disability insurance system and the unemployment insurance system is 70 percent of the previous wage. The entitlement period depends on labour market history, and for eldery workers with a long labour market history entitlement to unemployment insurance benefits can be 60 months. On the other hand there are eligibility rules for obtaining benefits. To obtain disability insurance benefits, a medical examiner has to qualify the worker as insuitable for the job on medical grounds. Especially in the eighties formal eligibility rules were loosely interpreted, as a transition into disability was a mutual beneficial deal for worker and employer. In the meanwhile the interpretation of

\footnotetext{
11 Until 1999, early retirement benefits were financed by a pay-as-you-go system. From 1999 on, the early retirement systems of the different sectors were gradually replaced by funded systems, and employees obtained some, limited, choice to determine premium contributions, thereby influencing the pension benefits and the age of eligibility. These changes are not yet relevant for our sample.
} 
medical eligibility grounds has been sharpened and a system of experience rating was introduced in disability insurance. To obtain unemployment benefits, a worker has to become formally unemployed. In this paper we will distiniguish job exit into disability and unemployment as separate exit routes from retirement for two reasons. If there is a mutual beneficial deal of exit into one of these systems, there may be a choice element in the job exit transition and the level of wealth may play a role. But, second, if disability is entirely accidental and governed by bad health and if unemployment is truly involuntary, the job exit transition is not the result of choice and economic theory does not predict a causal effect between the job exit and the level of private wealth.

\section{The data}

We use data from the Dutch Socio-Economic Panel for the years 1995 through 2002. This panel survey was initiated in 1984, but through the years there have been minor and major changes in the setup. The first six years, 1984-1989, questionnaires were conducted twice a year, in april and october, while income data was collected in the october wave. The year 1987 was the first year in which data on assets and debts were collected. In 1990 the setup was changed and data were collected each year in May. Also the collection of income data changed considerably. So far income had been collected in terms of net income earned in the month of the survey. From 1990 on the survey in May collects income on the previous fiscal (calendar) year, and the information resembles the information that individuals need to provide to the tax authorities each year. Information on earnings is expressed in gross earnings per year, with separate information on taxes paid. In the early nineties there were no major changes in the survey anymore, but the formulation of survey questions was not entirely stable from wave to wave. We chose to use data from the periods 1995 through 2002 as questions on participation in pension

schemes and reasons for job exit were available and stable through these years. The year 2002 is the final year in which the survey was conducted. No more information is collected for subsequent years: the survey has stopped now.

To construct our data, we selected male individuals appearing in any of the survey 
waves in 1995 through 2001 in the age range of 48 through 64 who report to be employed. We use the subsequent wave to check the labour market state of the same individuals in the next year. An important condition is that information on the same individual is present in the next wave. Individuals that are subject to attrition of any kind are dropped from the data. This requires the assumption that unobserved factors in the attrition process are uncorrelated with unobservables in the determination of the labour market state. Thus, we can determine whether an individual exits from the job from one year to another. We do not consider whether a job exit is definite. We add information on the individuals' background characteristics from the first wave of each pair of waves, except for income. For instance, if we select an employed individual in the age range 48-64 in the year 1995, we use the wave in 1996 to check whether a job exit took place, and use information on assets, debts, marital status, pension scheme participation, etc, from the May 1995 wave. However, since income refers to the previous fiscal year, we use income information from the May 1996 wave, which refers to the calendar year (JanuaryDecember) 1995. Since the survey in May 1996 collects information on the wage income earned in 2005 and also on the number of months worked in that year, we can determine the monthly wage income of each individual in the year 1995, which is assigned to the monthly wage income earned in May 1995. This example is for the years 1995-1996 but the same holds for any other pairs 1996-1997 through 2001-2002. Self-employed individuals are excluded: the survey does not apply the questions on assets and debts to the self-employed. In the waves of 1996 through 2001, information on income in the previous fiscal year is expressed in guilders. In the year 2002, the information on income has been collected in euro. We have converted this information in euro to guilders by multiplying the amount by 2.20371 which is the euro to guilder exchange rate.

Pooling the (pairs of) waves with information on job exits results in 3732 observations. Because of the panel nature of the survey, individuals who have not yet exited from the job and are still participating in the survey, may appear in more waves. Thus, the 3732 observations are on 1133 different individuals.

We will discuss the variables that we include in our sample by looking at tables 1 and 2. The tables contain sample descriptives on continuous and count variables (table 
1) and dummy indicators (table 2). In table 1 we see that the average age (measured in years) is 52.6. Since we selected individuals in the age range of 48 through 64 , this indicates that there are relatively more 'younger-elderly' in our sample. This is related to higher job exit rates from a certain age on (see later).

The decision to retire may be influenced by the presence of children in the household. We see that on average there is less than 1 child (0.88) in the household. In table 2 we see that in 47.0 per cent of the households no child is present (anymore).

There is some information on participation in pension schemes in the survey. The information on properties of the pension scheme, though, is very limited. Before we discuss this information, we emphasize that it is not the purpose of this paper to analyse the impact of the properties of the pension system on job exit: our aim is to measure the impact of wealth, assets, and debt position on job exit. But participation in a pension scheme could be a reason for postponing job exit, even if the individual has a high wealth level, and, moreover, people with a high wealth level also may have a favourable pension arrangement. So the reason to include this information on pension schemes is, in the first place, to isolate the impact of wealth on job exit.

In the survey, each individual is asked whether he participates in an employee pension scheme. Table 2 shows that this is the case for 89.7 per cent of the respondents, whereas 1.8 per cent does not know the answer to this question. Usually, the pension premium is withheld automatically from the salary, and the worker does not have to undertake any action to pay the pension premiums. However, 4.1 per cent of the individuals claims to pay a pension premium directly. For these individuals, information is collected on the premium contribution paid: the average contribution is 253 guilders. In 73.8 per cent of the cases the employer contributes to the payment of the premium, according to the survey respondents.

Some individuals participate in an individual pension scheme, initiated by themselves. The motives for participating in an individual pension scheme can be quite diverse and are not recorded in the survey. We can imagine that poor employee pension schemes or many job changes in the past may add to the participation in individual pension schemes, but an alternative motive may come from high income people who have more financial 
means to invest in individual pension schemes. In any case, someone participating in an individual pension scheme has a certain awareness of his financial situation after retirement, and including information on participation in individual pension schemes in the job exit rate may proxy this awareness as well as the 'true' impact of the pension scheme itself. We see that 15.6 per cent of the respondents participates in an individual pension scheme. The sample average of the monthly contribution is 413 guilders.

We have included some other properties of the job. We see that 31.9 per cent of the respondents characterize themselves as a civil servant. Early retirement schemes of civil servants are known to be more generous and wide spread than for workers in the private sector. At this age, most workers (96.0 per cent) have a 'permanent' job.

The longitudinal dataset of the Socio-Economic Panel (SEP) provides aggregate measures of assets and debts. The aggregate measures are computed by aggregating information on several asset and debt categories. Table 1 contains the averages of these aggreagate measures. Total liquid wealth is obtained by Statistics Netherlands by aggregating the amounts on the current accounts and savings accounts, bonds, stocks, money lent, value of jewelry, antiques, and cars. ${ }^{12}$ The mean value of total liquid assets is 69942 . As the distribution of liquid wealth usually is quite skewed, table 1 also reports the median, which is 28095. Total debts (excluding the value of mortgage debt outstanding) are obtained by aggregating personal loans at banks and credit institutions, loans to finance purchases, and remaining (including money borrowed from family and friends). The mean value of debt outstanding is only 6907 guilders, and the median is zero, indicating that over 50 per cent of the respondents has no outstanding debts. Taking the difference of the aggregate measure for total liquid wealth and debt outstanding gives a measure of net total liquid wealth. Alternative measures of assets and debts can be obtained by incorporating the value of the house and the mortgage debt. The average value of the house of the sample respondents is 322700 , and the average mortgage debt is 118070 . In our empirical analysis we will examine the impact of the various measures of wealth on the job exit probability. Note that the basic theoretical framework of the previous

\footnotetext{
${ }^{12}$ Not every household has possesions in each category. Money in current and savings account is most common. Jewelry and antiques applies to few households only. In this paper we only consider aggregate wealth and not the relation between portfolio composition and retirement.
} 
section uses total net wealth as a variable. Nevertheless it is imaginable that, due to credit market imperfections, the impact of total assets on the job exit probability need not necessarily be exactly the opposite of the impact of total debts. Therefore, we will also allow for differences in the impacts of total assets and debts on job exit.

The avarage monthly wage income is 4724 guilders and the other income is 242 guilders. Both the theoretical model in section 2 and the description of the early retirement system in section 3 show that the future pension benefits are directly based on the final earnings. We do not include an explicit measure for pension wealth in the regression model. We do not observe pension wealth in the data, but any constructed present value measure of future pension benefits would be a function of the observed final earnings. By including the earnings, we therefore can identify the impact of private wealth from the impact of pension benefits.

Section 3 also showed that replacement rates and age of eligibility to early retirement benefits varies by sector. The survey contains detailed information on the industrial sector of workers. Given the number of transitions observed, we have aggregated information on industrial sectors in 12 catergories.

We also make use of indicators for the level of education ranging from primary education (level 1) to university (level 5). In addition, we use indicators for the sector that respondents have been educated for, including technical, economic/administrative, general, and services. These sectors are less detailed than the industry dummies. We use them alternately with the industry dummies. In the empirical analysis we estimate our base specification with these broad sectors, and we do a sensitivity analysis with the more detailed industry dummies.

The data contain information on the labour market state of the spouse: 51 percent of the sample respondents have an employed spouse (about 58.4 percent of the married men). The labour market state of the spouse may in fact be jointly determined with the husband's. Gustman and Steinmeier (2000) model the joint retirement of dual-career families. Due to possible endogeneity we do not include the spouse's labour market state and income in the base specification. However, we carried out a sensitivity analysis to check whether the impact of wealth on retirement would change if the spouse's variables 
are included.

We have 3732 pooled observations in our sample of 1133 different individuals that have been selected on employment status (having a job) and age (48-64), and we track their labour market state the next year: 211 (5.7 per cent) is observed not to have a job the next year. Respondents that left their job are asked to report the reason for their job exit from a list of possibilities. The most important reasons for job exit listed are being fired, end of contract, shut down of firm, illness/disability, early retirement/living of one's investments, ${ }^{13}$ pensioned, remaining (not specified any further). We have merged several of these categories. We made a category 'unemployed' for being fired, termination of contract, and shut down of a firm: 15.6 per cent of the job exiters indicate that unemployment is the reason for job exit. We also merged several categories of retirement. Note that the retirement categories are self-reported, and that we cannot distinguish whether someone goes on early retirement according to the narrow definition of the early retirement system, or whether someone decides to live on interest. Moreover, the category 'pensioned' is also recorded by some job exiters younger than 60, so it can indicate that the reported 'being pensioned' may also include early retirement in the narrow sense. Therefore, we made one category 'retirement': 65.9 per cent of the job exiters indicates that the job loss is due to retirement. Finally, there is a category 'remaining' which does not further specify the reason for job exit. The respondents could also report job exit for reasons like 'marriage', 'taking care of the children', and 'taking care of a family member', but none of the respondents in our subsample reported any of these categories as the reason for their job exit. The category 'remaining' does not include these type of reasons for job exit, and it seems likely that it refers to job quits.

Overall, the job exit rate is 5.7 per cent. The differences by age are however large as shown in table 4 and figure 1 . First, note that the age indicated in the figure and the table is the age of selection in the sample, while employed, so the job exit takes place 1 year later at the indicated age +1 . The exit rates for the workers in the age range of 48 through 53 is around 1 to 2 percent, and peaking to 44.3 per cent at the age of 60 . It

\footnotetext{
13 In Dutch: 'rentenieren'.
} 
should be mentioned that the number of observations decreases with age. ${ }^{14}$

Unfortunately the survey does not contain information on eligibility to early retirement benefits. Age is an important determinant of eligibility to early retirement and in the empirical analysis we do a sensitivity analysis with a flexible specification in age, but different early retirement schemes can have a (somewhat) different age of eligibility. Moreover, the age of eligibility differs by sector and we analyze the sensitivity of our results to the inclusion of different sector dummies. Job tenure is also a determinant of early retirement. Most early retirement schemes in the Netherlands contain the condition that someone must have worked for the employer the past 10 years to become eligible for early retirement at the age of eligibility. The survey contains information on the starting date of the present job, but job tenure itself is an endogenous variable: we model the probability of job exit, but the probability of observing a given job tenure consists of a sequence of probabilities of not experiencing a job exit during the length of the job. This requires the specification of job exit probabilities over the entire past, which will cover many years out of the sample period. Thus, we abstain from using information on job tenure. However, note that we include various additional covariates that are likely to correlate with eligibility to early retirement, like the education level, information on sectors, on being a civil servant, and participation in pension schemes. Finally, note that the retirement state as we define it is not restricted to early retirement in the sense of the early retirement system, but includes retirement, living on one's investements, as well as other reasons for job exit.

We do not include explicit information on expected pension benefits, but the theoretical model in section 2 highlighted the role of the current wage in determining the level of pension benefits. Pension schemes in the Netherlands are of the defined benefit type and benefits are based in the final wage.

\footnotetext{
${ }^{14}$ We have compared the exit rates by age in our sample with population exit rates provided by Statistics Netherlands for the years 1999-2001 (see CBS, 2004). The order of magnitude and the age pattern of the exit rates in our sample compare well with the population rates for the ages of 54 and higher. For younger ages the exit rates in our sample seem to be systematically lower than the exit rates reported by Statistics Netherlands.
} 


\section{Empirical analysis}

\subsection{The empirical model}

We use a multinomial logit model to analyse the impact of wealth on job exit. We aggregate the four reasons to exit a job, listed in table 3, into two categories, to have a reasonable number of observations in each categorie. We have joined the categorie 'other' with the categorie '(early) retirement/living of one's investments'. It is not specified what are the precise motives to exit for respondents who indicated to have an 'other' reason to exit, but we know that it is not (early) retirement, living of one's investments, layoff, termination of contract, shut down of firm, illness and disability, marriage, or taking care of children or other family members, so it most likely that it represents a voluntarily job exit, a quit. For this reason it may suit better in the retirement categorie. The other job exit categorie is unemployment and disability. Figure 2 shows the sample job exit rates into the combined category unemployment/disability by age. The figure does not show a clear relationship between age and exit rates into this destination. Figure 3 shows the exit rates into the extended category (early) retirement. The age pattern resembles the age pattern of the total exit rate in figure 1, although exit rates before age 54 are even smaller. In the figures 4 and 5 we have expressed the use of the different exit routes by job leavers, split up by age. They show the fraction of job leavers that use the exit route unemployment/disability (figure 4) and (early) retirement (figure 5). The figures vertically add up to one, and we see that the use of unemployment/disability is concentrated among the younger job leavers, whereas older job leavers use (early) retirement relatively more often. Notably in the age range of 52 through 58 each exit route is used by some substantial fraction of job leavers. Above the age of 58 , the use of retirement as exit route dominates. A reason for this is the age of the eligibility in early retirement schemes, in combination with a high fraction of workers that are eligible for early retirement, the attractiveness of the early retirement scheme relative to other exit routes, and the eligibility conditions for the other exit routes. Below the age of 52 few job leavers exit by retirement.

Thus, for an individual $i$ selected in the sample in period $t$ and whose labour market 
state we keep track of in period $t+1$, we have three possible values for the outcome variable $d_{i t}$ : staying employed $(\mathrm{E})$, retirement $(\mathrm{R})$, and unemployment/disability $(\mathrm{U})$. The state of employment is our base category, such that the probabilities we specify below are job exit probabilities. If $x_{i t}$ is a vector of explanatory variables, we specify the probability of job exit to state $J$ as

$$
P\left(d_{i t}=J \mid x_{i t}\right)=\frac{\exp \left(x_{i t} \beta_{J}\right)}{1+\exp \left(x_{i t} \beta_{R}\right)+\exp \left(x_{i t} \beta_{U}\right)}, J=R, U
$$

with $\beta_{J}, J=R, U$ the parameter vectors measuring the impact of the explanatory variables $x_{i t}$ on the probability of job exit to state $J$. For the interpretation of the parameter estimates it is important to note that the parameter vector $\beta_{R}$ measures the impact of the variables $x_{i t}$ on job exit into (early) retirement, keeping constant the impact of these variables on job exit into unemployment/disability. The latter effect is measured by the parameter $\beta_{U}$ and affects the probability of job exit into (early) retirement by the denominator in (14). Thus, $\beta_{R}$ does not measure the total effect of $x_{i t}$ on the probability of job exit into (early) retirement. This is because of the competing risks nature of the model. In the extreme case, the total effect of a variable $x_{k, i t}$ may be opposite to the sign of $\beta_{k, R}$ : if the impact of a variable $x_{k, i t}$ on the probability of job exit into (early) retirement, measured by $\beta_{k, R}$ is positive, but there is also a very strong positive impact of this same variable on the probability of job exit into unemployment/disability $\beta_{k, U}$, the sign of the eventual effect of the job exit probability into (early) retirement may even reverse. This should be kept in mind when we present and discuss the tables with the parameter estimates: we will first discuss the estimates (the effects keeping constant job exit into alternative directions) and thereafter we present elasticities that measure the total effect of wealth on the job exit probabilities.

The model specification assumes that the explanatory variables $x_{i t}$ are uncorrelated with the errors of the extreme value distribution underlying the multinomial choice model for $d_{i t}$, and in particular this assumption is made for the wealth variable included in $x_{i t}$. More specific, the model assumes that there is no correlation in unobservables between wealth $A_{i t}$ and the labour market state the next period: any possible correlation between the two runs via the observables that are included in the regression. For this 
reason we include a rich set of regressors to capture any possible correlation. We include many observable covariates in the job exit probabilities to explain as much of the possible (spurious) correlation between wealth and job exit as possible. We include the information on participation in pension schemes, working as a civil servant, working in a permanent job, as well as income. These are all variables that are likely to correlate with the level of wealth, but also are likely to influence the probability of job exit. Nevertheless we should be careful in interpreting the impact of wealth on retirement that we find, especially when it comes to the question whether the effect we find is really a causal effect

Methods that try to allow for correlation in unobservables have to specify this correlation and moreover rely on exlcusion restrictions for identification. Bloemen (2002) specifies a model of transitions that includes random effects in the labour market transitions, and a wealth equation with random effects, and allows for correlation in the errors between the wealth equation and the transition process. His analysis also shows that it is extremely hard to find suitable exclusion restrictions to allow for endogeneity of wealth on basis of the theoretical framework outlined in section 2. Finally, note that the inclusion of random effects in the job exit rates itself, without specifying a process for wealth, does not solve the endogeneity problem.

\subsection{The parameter estimates}

Table 5 shows the estimation results of the multinomial logit model including measures of liquid wealth. Table 5a shows the parameter estimates of the job exit rate into unemployment, illness, and disability, whereas table 5b shows the results for (early) retirement. The regression in the first two columns includes total net liquid wealth as defined in section 3. Although the coefficient estimate of net liquid wealth in the job exit rate to unemployment/disability is positive, it is not significant at conventional levels. The $5 \mathrm{~b}$ shows that total net liquid wealth has a positive and significant effect on the exit rate into (early) retirement: this is in accordance with the theoretical prediction outlined in section 2 .

Before we continue our presentation of the impact of wealth on the job exit rate, 
we look at the other variables included in the regression. The number of children itself did not affect the exit rates, but the absence of children in the household has a positive impact on the job exit rate into (early) retirement: care for children seems to be a motive to continue working. The results presented in table 5 exclude the number of children, but inclusion of this variable does not change the impact of wealth that is found. We have merged singles, divorced, and widows into one category (the base) and only include a dummy variable for being married. There is weak evidence that married workers exit the job less often due to unemployment/disability (p-value of 0.101 ). We have also analyzed the impact of the inclusion of variables of the spouse. The inclusion of the spouse's labour market status and earnings may be criticised for the reason that the labour market decision of couples may be jointly determined. We have only used the variables for a sensitivity analyses. We found no impact of the labour market status, the earnings, and the non-labour income of the spouse on the probability to retire. However, workers with an employed spouse have a lower probability to exit into unemployment/disability. The impact of wealth on the job exit rates was not affected by the inclusion of the variables.

In section 3 we explained that eligibility conditions and replacement rates of pension benefits can be different for different sectors. The regression in table 5 include different sectors. It also includes a dummy variable for being a civil servant. The pension fund for civil servants, the ABP, is the largest pension fund in the Netherlands. We find no significant effects of the sector dummies. We have also done a sensitivity analysis with the more detailed industry dummies presented in section 4 . The inclusion of these dummy variables did not change the impact of wealth on the job exit rates that we have found.

Participation in an employee pension scheme makes it less likely that workers exit the job by unemployment/disability. Recall that for those who are participating in an employee pension scheme, we know whether the worker pays the premiums directly, and if so, we know the premium amount. The amount of the premium was not significant and is excluded from the regression in the table (but inclusion does not alter the result on wealth that was found). However, workers who do pay the premium directly have a 
higher job exit rate by both routes. It could indicate that the fact that the worker pays the premium directly means that he has also more freedom to choose the retirement age, and eligibility rules may be less stringent. Participation in individual pension schemes does not seem to affect the job exit rate by any route. Workers with a 'permanent' job are less likely to exit a job by unemployment/disability and are more likely to exit a job by (early) retirement. The latter probably indicates eligibility to pension benefits of workers with a 'permanent' job. Individuals with the lower levels of education seem to have a higher probability of job exit into (early) retirement than individuals with the highest level of education. The monthly wage income does not have a significant influence on job exit, but the coefficient is positive for both exit routes. Recall that the model in section 2 implies that there are opposing effects of the wage income on the probability of job exit. There is a positive income effect that makes it more likely that workers exit the job the higher is their wage income, but there is a negative effect that is stronger the lower are the replacement rates of the state of inactivity. The positive coefficient found suggests that the positive income effect dominates, but it is not strong enough to find a significant effect of wage income on job exit rates. The impact of other income on the job exit rates was somewhat puzzling. A priori we may expect that a higher level on non-labour income makes it more attractive to leave the job, at least if leisure is a normal good. We first included other income linearly in the job exit rate and found a significant negative effect on the job exit rate into (early) retirement. However, we found that this negative effect was driven by the observations with the highest values of non-labour income: we defined a dummy variable taking the value 1 for workers with more than the 95 per cent quantile of the sample distribution of other income ( 0 otherwise), and found that this variable entirely picked up the negative effect. In the regression in table 5 , we have added other income squared. The level of the coefficient of total net liquid wealth does not change much depending on whether we include other income linearly, add it squared, or add the dummy variable described above.

We have done sensitivity analyses to find out whether the positive and significant effect of total net liquid wealth on the job exit rate into (early) retirement may be caused by some observations in the tails of the distribution of wealth. We defined two 
dummy variables: one dummy variable that takes the value 1 for observations with a wealth level that exceeds the 95 per cent quantile of the sample distribution ( 0 otherwise) and another dummy variable that takes the value 1 for observations with a wealth level smaller than the 5 percent quantile of the sample distribution of wealth. These dummy variables turned out not to be significant, whereas the positive significant effect of wealth on the job exit rate into (early) retirement itself remained. We have also run a regression with total net liquid wealth squared: both the coefficient of wealth and wealth squared in the job exit rate into (early) retirement were positive, but the separate coefficients were not significant, indicating that wealth squared does not add to the explanation of the job exit rate and there is no such thing like a backward or forward bending pattern in the relation between wealth and the job exit rate into (early) retirement.

The next move is to look at the impact of alternative measures of wealth. Total net liquid wealth is obtained by subtracting total debt outstanding (excluding mortgage debt) from total liquid assets. The theoretical framework in section 2 concentrates on the impact of net total wealth, but there may be a difference in the separate impacts of assets and debts on job exit. For this reason, we have estimated the job exit probabilities with total liquid assets and debts separately. The results are in the final two columns of table 5. Again, we do not see any significant effect of these variables on the job exit probability into unemployment/disability. Total liquid assets have a positive and significant impact on the job exit rate into (early) retirement. Total debt shows a negative coefficient estimate for the job exit probability into (early) retirement, but the coefficient estimate is not significant. Note that the coefficient of total liquid assets is almost the same as the coefficient estimate of total net liquid wealth in the first regression. Recall from the descriptives in section 3 that over 50 per cent of the sample respondents do not have any debts, and that the mean amount of debts is small compared to the amount of liquid assets.

There has been a discussion in the literature on the value of the house as a stock of assets that may be released to finance future consumption (see, for instance, Venti and Wise (1991)). After retirement, individuals may sell the house, and move into a smaller and cheaper appartment. Therefore we consider an alternative measure of assets 
and an alternative measure of debts. To the liquid assets considered so far, we add the value of the house to obtain this alternative measure. Moreover we add the value of the mortgage debt outstanding to the debts measure used so far. We estimated a multinomial logit model for the job exit rates including these alternative wealth measures, and the results can be found in the tables $6 \mathrm{a}$ and $6 \mathrm{~b}$. Table $6 \mathrm{a}$ contains the results for job exit into unemployment and disability. The first two columns show the impact of total net wealth. Although the coefficient estimate is positive, it is not significantly different from zero. The final two columns show the results of the separate inclusion of total assets and total debt. Again, the coefficients have the predicted sign (the asset coefficient is positive and the debt coefficient is negative) but they are not significantly different from zero. Table $6 \mathrm{~b}$ shows the results on the job exit rate into (early) retirement. Here we see that total net wealth has a significantly positive effect on the job exit rate into (early) retirement. If assets and debts are included separately, we also find significant effects: a higher value of assets increases the job exit rate, and a higher value of debts decreases the job exit rate into (early) retirement.

This result shows that with different measures of wealth, with entirely different orders of magnitude (see table 1), we find a positive significant impact of wealth on the probability of job exit into (early) retirement. However, a significant effect of wealth on job exit into unemployment/disability cannot be detected. The model in section 2 implies that wealth enters the job exit rate as a choice factor. In the discussion of the model in section 2 we concluded that the impact of wealth on job exit will be weakened if job exit is determined by exogenous lay-off rates or eligibility rules. Finding no significant effect of wealth on job exit into unemployment/disability suggests that job exit by these routes are less governed by individual choice and more by demand side and eligibility factors, in spite of the 'consensus between employers and workers' stories about job exit of elderly workers into unemployment and disability. ${ }^{15}$

Moreover, the results show that a higher mortgage debt may be a motive for workers

\footnotetext{
${ }^{15}$ This result is not inconsistent with an analysis by Lindeboom (1998), who finds that the replacement rate of disability (unemployment) insurance benefits has no significant effect on job exit into disability (unemployment), which also indicates that the possibilities of workers to 'choose' for these exit routes may be limited.
} 
to postpone retirement from the labour force.

So far we have distinguished two different exit routes, and the different results for the different exit routes suggest that it is important to make that distinction. However, the positive effect of wealth on job exit may hold for job exit in general, and moreover, we may obtain more precise estimates of the effect of wealth on job exit if we merge the job exit routes into one exit state. Note that the multinomial logit model also allows us to evaluate the impact of wealth on the total probability of job exit (or, equivalently, on the staying-on probability), and we will later on present results on elasticities of the stayingon probability with respect to wealth, but as a sensitivity check we have estimated a logit model to estimate the impact of wealth on job exit, aggregating the different exit routes. We do not report complete tables of estimation results, but we mention the key outcomes. We found a positive effect of total net liquid wealth on the job exit probability, but it was not significant at the 5 per cent level: its p-value is 0.11 . Splitting up total net liquid wealth into liquid assets and debts (excluding mortgage) again showed a positive but insignificant effect of liquid assets, and a negative effect of outstanding debt, that is significant at the 10 per cent level. The results support the importance of making a distinction between different exit routes: merging exit routes does not lead to a higher precision of the effect of wealth on job exit, which indicates that the insignificant effect of wealth on job exit into unemployment and disability, found with the multinomial logit model, was not just driven by a low number of observations of job exits in this category. If we add the value of the house to assets and the value of the mortgage to debt, we find a positive effect of total assets on the job exit probablity that is significant at the 10 per cent level, and a negative effect of debt that is not significant (with a p-level of 0.11).

\section{$5.3 \quad$ Elasticities}

So far we have discussed the coefficient estimates of the multinomial logit model. The coefficients indicate the impact of the variables on job exit in a given direction, keeping constant job exit in an other direction. We will now present the total effect of wealth on the job exit probabilities in different directions, as well as on the staying-on probability, by presenting the elasticities of these probabilities with respect to wealth. The elasticities 
we present are point elasticities, evaluated at certain values of the explanatory variables. Note that net wealth is a variable that can take both positive and negative values, but that need not deteriorate the function of the elasticity as a means to summarize the impact of wealth on job exit: we will evaluate the elasticity in the sample's mean and median values of wealth.

If we denote the job exit probability into direction $J, J=U, R$, evaluated in characteristics $x_{i t}$ by $P_{J}\left(x_{i t}\right), J=U, R$, the elasticity of the probability of job exit into (early) retirement with respect to variable $x_{k, i t}$ is

$$
\epsilon_{R, k}=\beta_{k, R} x_{k, i t}\left(1-P_{R}\left(x_{i t}\right)\right)-\beta_{k, U} x_{k, i t} P_{U}\left(x_{i t}\right)
$$

The form of the elasticity in (15) reveals several properties. First, we see that the effect $\beta_{k, U}$ of the variable $x_{k, i t}$ on the exit into the alternative exit state of unemployment/disability, has an opposing effect: if $x_{k, i t}$ raises the opportunity to exit by unemployment/disability, its impact on exiting by retirement will be smaller. The size of this opposing effect also depends on the size of the probability $P_{U}\left(x_{i t}\right)$ of exiting to that alternative state. This is the competing risk property of the multinomial choice framework. Second, the size of the elasticity is affected by $1-P_{R}\left(x_{i t}\right)$. This reflects that the elasticity is a relative measure: if $P_{R}\left(x_{i t}\right)$ is small, the relative change in the probability will be large. For the elasticity of the probability of job exit into unemployment/disability with respect to variable $x_{k, i t}$ we have a similar expression:

$$
\epsilon_{U, k}=\beta_{k, U} x_{k, i t}\left(1-P_{U}\left(x_{i t}\right)\right)-\beta_{k, R} x_{k, i t} P_{R}\left(x_{i t}\right)
$$

The elasticity in (16) is the mirror image of the elasticity in (15). Finally, the elasticity of the staying-on probability $P_{E}\left(x_{i t}\right)$ with respect to variable $x_{k, i t}$ is

$$
\epsilon_{E, k}=-\beta_{k, R} x_{k, i t} P_{R}\left(x_{i t}\right)-\beta_{k, U} x_{k, i t} P_{U}\left(x_{i t}\right)
$$

Since staying employed is chosen as the base category in our multinomial logit model, the expression (17) for the elasticity of staying employed is built up by the opposite effects of exiting by any exit route.

The base for evaluating the numerical values of the elasticities are the sample averages of all of the explanatory variables. Alternatively, we have also evaluated elasticities in 
the median values of wealth, keeping the remaining variables at their sample averages. Moreover, since the sample average of age is only 52.6 while job exit rates peak at the age of 60 , we have also evaluated elasticities at the age of 60 , keeping the other values at their sample average. Table 7 shows the resulting values of the elasticities. The upper panel shows the elasticities of the job exit probabilities and the staying-on probability with respect to net liquid wealth, and is obtained from the estimates in the first columns of table 5. It shows that the job exit rate into (early) retirement is the most sensitive with respect to changes in net liquid wealth: the elasticity evaluated in sample averages takes the value 0.11 , which is significantly different from zero. The elasticity of the job exit rate into unemployment/disability is positive but fairly small and not significantly different from zero. The elasticity of the staying-on probability with respect to net liquid wealth is negative but close to zero and insignificant. Evaluated at median wealth (second column of table 7) the qualitative conclusions remain the same but the quantitative outcomes differ. The elasticities evaluated at age 60 show some interesting differences. The elasticity of the job exit probability into unemployment/disability with respect to net liquid wealth has become negative, but still insignificant, although the coefficient in table 5 shows a positive effect. This means that in the computation of the elasticity according to (16) the competing risk effect of transiting into (early) retirement dominates at age 60 . We also see that the staying-on probability is more sensitive with respect to net liquid wealth at the age of 60 , although it remains insignificant. The second panel of table 7 shows the elasticities of the exit and staying-on probabilities with respect to net wealth, including the value of the house and the mortgage debt, corresponding to the estimates in the first columns of table 6. The job exit rate into (early) retirement shows a higher sensitivity with respect to this measure of wealth, compared to net liquid wealth. The elasticities for this exit route again are positive and significant. The third and the fourth panel of table 7 show the elasticities with respect to total assets (liquid + value of the house) and total debt (including mortgage debt), and correspond to the estimates in the final two columns of table 6 . For total assets, the qualitative results remain the same as before. However, we see larger values of the elasticities for all the probabilities. For instance, the elasticity of the job exit probability into (early) retirement, evaluated 
in sample means, now has a value of 0.32 , and is significantly positive. The elasticity of job exit into (early) retirement with respect to total debt is -0.31 and significantly smaller than zero.

In conclusion we can say that the job exit probability into (early) retirement is the only probability that reveals significant elasticities with respect to various measures of wealth, assets, and debt. They have the signs predicted by the theoretical framework. The probability of exit into unemployment/disability is fairly insensitive with respect to wealth, assets and, debt. The signs of the elasticities are usually in accordance with the theoretical predictions, but they are not significant. Even though the exit probability into (early) retirement shows a significant effect of wealth, we do not find significant impacts of wealth, assets, and debt on the staying-on probability, if we consider the staying-on probability as the residual of the exit rates into (early) retirement and unemployment/disability in the multinomial logit model, but recall that we found some significant effects if we merge the different exit routes. The effects of wealth, assets, and debt always have the sign predicted by theory.

\subsection{The fit of the model}

To give an indication of the fit of the models that we have estimated, we evaluate the fitted total job exit probability by age for the model variant that includes net liquid wealth (first columns of table 5). The sample job exit rates have been shown in figure 1 , and display a clear peak at the age of 60 . It is well known that peaks in empirical distributions are notoriously difficult to explain by structural economic factors, but the peak at age 60 would be very easy to reproduce by including a dummy variable for this age, which is not part of the model specification in table 5. The peak here is undoubtedly caused by the eligibility rules of the early retirement system. Figure 6 shows the mean fitted job exit probabilities by age. It shows a small peak at the age of 61 , but the drop in sample job exit rates between the ages of 60 and 64 is not reproduced by the model specification. Now it should be noted that the purpose of our analysis is not to explain

this peak in the job exit rate: we know where it comes from. Our purpose is to measure the impact of wealth on the job exit rates. But a legitimate question is whether the 
significant positive impact of wealth on the probability of job exit into (early) retirement will disappear if we allow for a more flexible specification in age. Therefore, we have done the following sensitivity analysis. We have specified two age dummies: one dummy that takes the value one for workers aged 60 (zero otherwise), and another dummy taking the value one for workers aged 61 through 63 (zero otherwise). We have added these age dummies to the multinomial logit specification with net liquid wealth, and we have re-estimated the model. The coefficient estimate of net liquid wealth for exit into (early) retirement is still positive and significant: it takes the value 0.0172 with a standard error of 0.0068. This is not much different from the numbers in table 5b. Figure 7 shows

the fitted job exit rates by age for this extended model specification showing a better fit of the peak at the age of 60 . In conclusion we may say that a more flexible model specification that leads to a better fit of the sample job exit rates does not change the significant impact of wealth on job exit into (early) retirement.

\section{Conclusions}

The level of private wealth, assets, and debt may become increasingly important for the decision of elderly workers to exit from the labour force as policies and trends seem to move away from social security wealth towards more private wealth. So far, there is little empirical evidence on the role of individual wealth in the job exit decision, as empirical studies have concentrated on the attractiveness provided by the exit routes themselves, like eligibility conditions and replacement rates. In this paper we study the impact of wealth on the job exit rates of elderly workers. We present a theoretical framework that, under some regularity conditions, predicts a positive effect of wealth on the decision to exit a job. The model also generates predictions for the impact of the earnings associated with the job. On the one hand, the wage income has a positive income effect on the decision to leave a job, provided that a higher wage income also generates higher benefits in the subsequent state of inactivity. But this positive impact of the wage income on job exit may turn negative if replacement rates of the benefits obtained in the inactive states are low enough and/or if the decision to stop working leads to lower pension benefits in 
future. There are several factors that may complicate the measurement of any effect of wealth on the job exit rate. First, the level of wealth may be positively correlated with favourable individual characteristics that may increase the probability to stay on the job. If individuals with a high level of wealth have better pension arrangements, they will be less likely to leave the job if that leads to a loss in eligibility to pension rights. For this reason, we include information on participation in employee pension schemes. Second, involuntary reasons for leaving a job will weaken the relation between job exit and wealth, which is a typical choice factor in the job exit rate. Third, eligibility rules to early retirement benefits may dominate the decision to retire.

For our empirical analysis we use data from the Socio-Economic Panel. We selected male workers in the age range of 48 through 64, who are present in the panel for two subsequent waves such that we can observe their labour market state one year later. Sample exit rates by age remain low until the age of 53, and they peak at the age of 60. The sample information allows us to distinguish different reasons for job exit. From this information we construct two different exit routes. The first includes job exit to (involuntary) unemployment, disability, and illness. The second includes early retirement, living on one's investments, and pensioning. The second exit route may a priori be more likely to be taken by choice, while the first is more likely to be taken by demand side factors, health risks, and eligibility conditions. However, it has been argued that transitions into unemployment and disability insurance of elderly workers is often governed by consensus between workers and employers and therefore may contain a hidden choice element as well.

We use a multinomial logit framework with three states: (i) exit into (early) retirement; (ii) exit into unemployment/disability; and (iii) our base, staying employed. We perform analyses with different measures of wealth: liquid wealth, without inclusion of the value of the house and the mortgage debt, and total wealth that does include the value of the house and mortgage debt. Moreover, we allow for separate effects of assets on the one hand, and outstanding debt on the other hand. We find that the two different measures of net wealth both increase the probability of job exit into (early) retirement, which is in accordance with the prediction. We do not find a significant effect of any 
of the wealth measures on the probability of job exit into unemployment/disability, although the coefficient estimates are positive. Moreover, we find that splitting up wealth into assets and debt, shows a significant positive effect of assets (both of liquid assets and assets including the value of the house) and a significant negative impact of debt (including mortgage debt) on the probability to exit the job by (early) retirement. These variables show the same signs on the probability of exiting the job into unemployment/disability, but are not significantly different from zero. Estimates of elasticities show that also the quantitative impact of wealth, assets, and debt is largest for job exit into (early) retirement. The impacts of wealth, assets, and debt on total job exit rates, without distinguishing the state of destination, are less clear. We have analysed total job exit rates in two ways. First, we have merged the different exit routes and simply done a logit analysis to analyse the impact of wealth on job exit. We still found some impact of wealth, assets, and debt on the job exit rate, but p-levels were lower and sometimes slightly higher than 0.10 . Second, the probability of staying-on follows from the multinomial logit specification, with employment as the base category. We have computed the elasticities of the probability of staying-on with respect to wealth, assets, and debt. Although the elasticities always have the signs that may be expected from theoretical arguments, they are never significant. The analysis shows that it is important to distinguish different states of destination. An interpretation of not finding a significant effect of wealth on job exit into unemployment/disability is that this exit route is hardly governed by individual choice, as wealth enters the exit rate as a component of the choice process.

As an additional result of our analysis, we find a positive, but insignificant effect of the wage income on the probability of job exit by any of the exit routes. The positive effect, though, suggests that the income effect of the wage income on job exit rates dominates, which is consistent with the relatively high replacement rates in the Netherlands.

For the interpretation of the impact of wealth on retirement that we have found it is important to emphasize that the result has been obtained under the assumption that, conditional on the set of regressors included, there is no unobserved heterogeneity in wealth that correlates with unobserved heterogeneity in the job exit rates. For this 
reason we have included a rich set of regressors. If the assumption is not satisfied, the impact of wealth on retirement that we found remains interesting, but it may not be completely be a causal effect. Many sensitivity analyses have been performed, using different measures of wealth, and using different regressors, and throughout the impact of wealth on retirement remained. The inclusion of earnings and industry dummies allows for the separation of private wealth from pension wealth.

Summarizing we may say that for the years 1995 through 2001, in which eligibility conditions for (early) retirement schemes were strongly dependent on age and in which replacement rates of (early) retirement schemes were relatively high, private wealth affects the job exit rates of elderly workers into (early) retirement. The role of private wealth in the retirement decision will increase if individuals obtain more freedom to determine their age of retirement, but also if replacement rates of pension benefits are decreased or if the age at which workers become eligible for retirement benefits is increased. 


\section{References}

Alessie, R, A. Lusardi, and A. Kapteyn (1999), Saving after Retirement: Evidence from Three Different Surveys, Labour Economics, Vol. 6 (2), pp. $277-310$.

Bloemen, H.G. (2002), The Relation between Wealth and Labour Market Transitions: An Empirical Study for the Netherlands, Journal of Applied Econometrics, Vol. 17, pp. 249-268.

Bloemen, H.G. and E.G.F. Stancanelli (2001), Individual wealth, reservation wages and transitions into employment, Journal of Labor Economics, Vol. 19, nr. 2. pp. 400-439.

Blundell R, T. Magnac and C. Meghir (1997), Savings and Labor Market Transitions, Journal of Business and Economic Statistics, Vol. 15, no. 2, pp. $153-164$.

CBS (2004), Oudere werknemers, 1999-2001, CBS Webmagazine, April 2004.

Danforth, J. P, (1979), On the Role of Consumption and Decreasing Absolute Risk aversion in the Theory of Job Search, in: Lippman, S. A.and McCall J.J (eds.), Studies in the Economics of search, North-Holland.

Gustman, A.L. and T.L. Steinmeier (2000), Retirement in Dual-Career Families: A Structural Model, Journal of Labor Economics, Vol. 18, No. 3, pp. 503-545.

Hamermesh, D. (1984), Consumption During Retirement: The Missing Link in the Life Cycle, Review of Economics and Statistics, Vol. 66 (1), pp.1-7.

Kapteyn, A, and K. de Vos (1998), Social Security and Labor-Force Participation in the Netherlands, American Economic Review, Vol. 88, no. 2, pp. 164-167.

Lindeboom, M, (1998), Microeconomic analysis of the retirement decision: the Netherlands, OECD, Economics Department working papers, no. 207. 
Stancanelli, E. G. F. (1999), Do the Richer Stay Unemployed Longer? An Empirical Study for the UK, Oxford Bulletin of Economics and Statistics, Vol. 61, pp. 295-314.

Stock, J.H. and D.A. Wise (1990), Pensions, the Option Value of Work, and Retirement, Econometrica, Vol. 58, no. 5, pp. 1151-1180.

Venti, S. and D. Wise (1991), Aging and the Income Value of Housing Wealth, Journal of Public Economics, Vol. 44 (3), pp. 371-397.

Woolley, M, (2004), Optimal Consumption and Investement with Labor Income Uncertainty and Endogenous Retirement, working paper, unc. 
Table 1: Sample descriptives

\begin{tabular}{|c|c|c|}
\hline \multicolumn{3}{|l|}{ Number of observations: $N=3732$} \\
\hline Variable & Mean & standard error \\
\hline Age & 52.6 & 3.5 \\
\hline \# Children living in the household & 0.88 & 1.0 \\
\hline $\begin{array}{l}\text { Pension premium (monthly, guilders) } \\
\text { only for workers participating } \\
\text { in employee pension system } \\
\text { and paying premium directly }(N=)\end{array}$ & 253 & 398 \\
\hline $\begin{array}{l}\text { Pension premium (monthly, guilders) } \\
\text { only for workers participating in } \\
\text { an individual pension scheme }\end{array}$ & 413 & 651 \\
\hline $\begin{array}{l}\text { Total liquid assets (guilders) } \\
\text { (Median): }\end{array}$ & $\begin{array}{r}69942 \\
(28095)\end{array}$ & 145187 \\
\hline $\begin{array}{l}\text { Total debt outstanding (excl. mortgage) } \\
\text { (Median): }\end{array}$ & $\begin{array}{r}6907 \\
(0)\end{array}$ & 33610 \\
\hline $\begin{array}{l}\text { Net total liquid wealth (guilders) } \\
\text { (Median): }\end{array}$ & $\begin{array}{r}63035 \\
(24878)\end{array}$ & 143880 \\
\hline $\begin{array}{l}\text { Value of house } \\
\text { (Median) }\end{array}$ & $\begin{array}{r}322700 \\
(280000)\end{array}$ & 363639 \\
\hline $\begin{array}{l}\text { Value of mortgage debt outstanding } \\
\text { (Median) }\end{array}$ & $\begin{array}{r}118070 \\
(8000)\end{array}$ & 380134 \\
\hline $\begin{array}{l}\text { Total assets (including value house) } \\
\text { (Median): }\end{array}$ & $\begin{array}{r}392642 \\
(324950)\end{array}$ & 443613 \\
\hline $\begin{array}{l}\text { Total debt (including mortgage) } \\
\text { (Median): }\end{array}$ & $\begin{array}{r}110775 \\
(84750)\end{array}$ & 122682 \\
\hline $\begin{array}{l}\text { Net total wealth (liquid }+ \text { illiquid) } \\
\text { (Median): }\end{array}$ & $\begin{array}{r}281867 \\
(199209)\end{array}$ & 395804 \\
\hline $\begin{array}{l}\text { Net monthly wage income (guilders) } \\
\text { (Median): }\end{array}$ & $\begin{array}{r}4724 \\
(4250)\end{array}$ & 3054 \\
\hline $\begin{array}{l}\text { Other income (monthly) } \\
\text { (Median): }\end{array}$ & $\begin{array}{r}242 \\
(0)\end{array}$ & (1996) \\
\hline $\begin{array}{l}\text { Earnings spouse (monthly, if employed) } \\
\text { (Median) }\end{array}$ & $\begin{array}{r}1878 \\
(1608)\end{array}$ & (2508) \\
\hline $\begin{array}{l}\text { Other income spouse } \\
\text { (Median) }\end{array}$ & $\begin{array}{r}938 \\
(0)\end{array}$ & (7076) \\
\hline
\end{tabular}


Table 2: Sample descriptives

\begin{tabular}{|c|c|}
\hline \multicolumn{2}{|l|}{ Number of observations: $N=3732$} \\
\hline & Percentage \\
\hline \multicolumn{2}{|l|}{ Education Level: } \\
\hline 1 (lowest) & 6.0 \\
\hline 2 & 14.2 \\
\hline 3 & 47.4 \\
\hline 4 & 21.7 \\
\hline 5 & 9.5 \\
\hline \multicolumn{2}{|l|}{ Education type: } \\
\hline Technical & 32.1 \\
\hline Economic/administrative & 24.8 \\
\hline General & 17.5 \\
\hline Services & 25.0 \\
\hline No children in the household & 47.0 \\
\hline 'Permanent' job & 96.0 \\
\hline Civil servant & 31.9 \\
\hline Participating in employee pension scheme & 89.7 \\
\hline Unknown whether part. in pens. scheme & 1.8 \\
\hline Pays contribution directly & 4.1 \\
\hline The employer contributes to premium & 73.8 \\
\hline Participates in individial pension scheme & 15.6 \\
\hline Married & 88.0 \\
\hline Divorced & 6.5 \\
\hline Widowed & 1.2 \\
\hline Single & 4.3 \\
\hline Employed spouse (sample percentage) & 51.4 \\
\hline Still employed next year & 94.3 \\
\hline \multicolumn{2}{|l|}{ Industry: } \\
\hline Agriculture, fishing & 1.0 \\
\hline Food, textile & 9.0 \\
\hline Chemistry, rubber & 4.2 \\
\hline Production of Machines, instruments & 7.2 \\
\hline Construction & 8.3 \\
\hline Retail and trade & 8.9 \\
\hline Transport & 8.1 \\
\hline Finance, commercial services & 11.8 \\
\hline Public government, education & 26.0 \\
\hline Health care & 5.7 \\
\hline Remaining services, public utility & 4.2 \\
\hline Other, missing & 5.5 \\
\hline Wave 1995 & 12.8 \\
\hline Wave 1996 & 13.5 \\
\hline Wave 1997 & 13.7 \\
\hline Wave 1998 & 14.4 \\
\hline Wave 1999 & 14.7 \\
\hline Wave 2000 & 15.9 \\
\hline Wave 2001 & 15.1 \\
\hline
\end{tabular}


Table 3: Job leavers: self-reported reasons to exit

\begin{tabular}{lr}
\hline Number of Job Leavers & 211 \\
\hline Reason for exit & Percentage of job leavers \\
\hline Became unemployed & 15.6 \\
Illness Disability & 11.9 \\
(Early) retirement/living of one's investments & 65.9 \\
Other & 6.6 \\
\hline
\end{tabular}


Table 4: Job exit rates by age

\begin{tabular}{lr}
\hline Number of Job Leavers & 211 \\
Number of Stayers & 3521 \\
\hline & Exit rate $(\%)$ \\
Total & 5.7 \\
Age: & \\
48 & 1.3 \\
49 & 1.2 \\
50 & 2.0 \\
51 & 1.1 \\
52 & 0.8 \\
53 & 1.8 \\
54 & 8.0 \\
55 & 6.1 \\
56 & 7.3 \\
57 & 8.2 \\
58 & 13.5 \\
59 & 29.6 \\
60 & 44.3 \\
61 & 34.3 \\
62 & 19.1 \\
63 & 14.3 \\
\hline
\end{tabular}


Table 5a: Results of multinomial logit model

with liquid assets and debt outstanding (excl. mortgage)

The Job Exit Rate with Destination Unemployment, Illness, and disability

\begin{tabular}{|c|c|c|c|c|}
\hline \multirow[b]{2}{*}{ Variable } & \multicolumn{2}{|c|}{ Net Liquid Wealth } & \multicolumn{2}{|c|}{$\begin{array}{l}\text { Liquid assets and } \\
\text { Debts Separately }\end{array}$} \\
\hline & $\begin{array}{r}\text { Parameter } \\
\text { Estimate }\end{array}$ & $\begin{array}{r}\text { Standard } \\
\text { Error }\end{array}$ & $\begin{array}{r}\text { Parameter } \\
\text { Estimate }\end{array}$ & $\begin{array}{r}\text { Standard } \\
\text { Error }\end{array}$ \\
\hline Log-likelihood & -682.44 & & -679.79 & \\
\hline Ln Age & 365.5 & 237.7 & 379.9 & 239.3 \\
\hline Ln Age Squared & -45.6 & 29.9 & -47.4 & 30.1 \\
\hline Education level 1 (lowest) & 0.78 & 0.82 & 0.75 & 0.82 \\
\hline Education level 2 & -0.65 & 0.69 & -0.69 & 0.69 \\
\hline Education level 3 & 0.18 & 0.53 & 0.15 & 0.53 \\
\hline Education level 4 & -0.11 & 0.57 & -0.16 & 0.57 \\
\hline Technical & 0.51 & 0.39 & 0.49 & 0.39 \\
\hline Economic/administrative & 0.14 & 0.42 & 0.19 & 0.42 \\
\hline General & -0.11 & 0.58 & -0.07 & 0.58 \\
\hline No Children in household & -0.12 & 0.30 & -0.14 & 0.30 \\
\hline Married & $-0.62^{*}$ & 0.38 & $-0.63^{*}$ & 0.38 \\
\hline Civil Servant & -0.30 & 0.36 & -0.28 & 0.36 \\
\hline Part. in employee pension scheme & $-1.22^{* *}$ & 0.61 & $-1.21^{* *}$ & 0.61 \\
\hline Worker pays premium directly & $1.26^{* *}$ & 0.50 & $1.33^{* *}$ & 0.50 \\
\hline Employer attributes to premium & $0.89^{*}$ & 0.54 & $0.91^{*}$ & 0.54 \\
\hline Permanent job & $-2.16^{* *}$ & 0.39 & $-2.15^{* *}$ & 0.40 \\
\hline Part. in individual pension scheme & -0.02 & 0.38 & 0.02 & 0.38 \\
\hline 1995 & 0.25 & 0.46 & 0.26 & 0.46 \\
\hline 1996 & 0.01 & 0.47 & 0.00 & 0.47 \\
\hline 1997 & -0.23 & 0.49 & -0.19 & 0.49 \\
\hline 1998 & -0.31 & 0.48 & -0.29 & 0.48 \\
\hline 1999 & -0.45 & 0.50 & -0.44 & 0.50 \\
\hline 2000 & -0.55 & 0.52 & -0.56 & 0.52 \\
\hline Monthly earnings & 0.022 & 0.038 & 0.024 & 0.037 \\
\hline Other income/1000 & 0.46 & 0.30 & $0.55^{*}$ & 0.31 \\
\hline Other income/1000 squared & -0.043 & 0.033 & -0.047 & 0.032 \\
\hline Total net liquid wealth/10000 & 0.00013 & 0.00932 & & \\
\hline Total liquid assets/10000 & & & -0.0035 & 0.0100 \\
\hline Debt/10000 & & & -0.26 & 0.19 \\
\hline Intercept & -733.9 & 472.9 & -762.5 & 476.0 \\
\hline
\end{tabular}


Table 5b: Results of multinomial logit model

with liquid assets and debt outstanding (excl. mortgage)

The Job Exit Rate with Destination (Early) Retirement

\begin{tabular}{lrrrr}
\hline & Net Liquid Wealth & \multicolumn{2}{c}{ Liquid assets and } \\
& & & Debts Separately \\
\hline Variable & Parameter & Standard & Parameter & Standard \\
& Estimate & Error & Estimate & Error \\
\hline Ln Age & 223.0 & 234.7 & 230.2 & 235.3 \\
Ln Age Squared & -24.0 & 29.1 & -24.9 & 29.1 \\
Education level 1 (lowest) & 0.91 & 0.58 & 0.87 & 0.58 \\
Education level 2 & $1.12^{* *}$ & 0.48 & $1.10^{* *}$ & 0.47 \\
Education level 3 & $1.08^{* *}$ & 0.44 & $1.03^{* *}$ & 0.44 \\
Education level 4 & 0.43 & 0.45 & 0.37 & 0.45 \\
Technical & -0.10 & 0.26 & -0.11 & 0.27 \\
Economic/administrative & 0.12 & 0.29 & 0.16 & 0.29 \\
General & 0.17 & 0.34 & 0.17 & 0.34 \\
No Children in household & $0.51^{* *}$ & 0.23 & $0.51^{* *}$ & 0.23 \\
Married & 0.20 & 0.29 & 0.21 & 0.29 \\
Civil Servant & 0.24 & 0.22 & 0.25 & 0.22 \\
Part. in employee pension scheme & -0.37 & 0.36 & -0.36 & 0.36 \\
Worker pays premium directly & $0.87^{* *}$ & 0.40 & $0.87^{* *}$ & 0.40 \\
Employer attributes to premium & -0.22 & 0.27 & -0.22 & 0.27 \\
Permanent job & $1.16^{* *}$ & 0.56 & $1.17^{* *}$ & 0.56 \\
Part. in individual pension scheme & -0.49 & 0.34 & -0.44 & 0.35 \\
1995 & $1.10^{* *}$ & 0.37 & $1.10^{* *}$ & 0.37 \\
1996 & 0.44 & 0.39 & 0.44 & 0.39 \\
1997 & $0.99^{* *}$ & 0.35 & 1.00 & 0.35 \\
1998 & 0.53 & 0.36 & 0.54 & 0.36 \\
1999 & 0.15 & 0.38 & 0.15 & 0.38 \\
2000 & 0.27 & 0.36 & 0.25 & 0.36 \\
Monthly earnings & 0.023 & 0.026 & 0.025 & 0.025 \\
Other income/1000 & -1.01 & 1.07 & -1.05 & 1.06 \\
Other income/1000 squared & -0.61 & 0.95 & -0.58 & 0.94 \\
Total net liquid wealth/10000 & $0.0176^{* *}$ & 0.0068 & & \\
Total liquid assets/10000 & & & $0.0171^{* *}$ & 0.0068 \\
Debt/10000 & & & -0.095 & 0.066 \\
Intercept & -514.4 & 473.9 & -529.0 & 475.1 \\
\hline **: significant at 5 per cent level & & & & \\
$*$ : significant at 10 per cent level & & & & \\
\hline
\end{tabular}


Table 6a: Results of multinomial logit model with assets (including house) and debt (including mortgage)

The Job Exit Rate with Destination Unemployment, Illness, and disability

\begin{tabular}{|c|c|c|c|c|}
\hline \multirow[b]{2}{*}{ Variable } & \multicolumn{2}{|l|}{ Net Wealth } & \multicolumn{2}{|c|}{$\begin{array}{l}\text { Assets and } \\
\text { Debts Separately }\end{array}$} \\
\hline & $\begin{array}{r}\text { Parameter } \\
\text { Estimate }\end{array}$ & $\begin{array}{r}\text { Standard } \\
\text { Error }\end{array}$ & $\begin{array}{l}\text { Parameter } \\
\text { Estimate }\end{array}$ & $\begin{array}{r}\text { Standard } \\
\text { Error }\end{array}$ \\
\hline Log-likelihood & -683.89 & & -682.01 & \\
\hline Ln Age & 366.4 & 237.7 & 368.1 & 237.9 \\
\hline Ln Age Squared & -45.7 & 29.9 & -45.9 & 29.9 \\
\hline Education level 1 (lowest) & 0.78 & 0.83 & 0.75 & 0.84 \\
\hline Education level 2 & -0.65 & 0.69 & -0.68 & 0.70 \\
\hline Education level 3 & 0.18 & 0.53 & 0.16 & 0.54 \\
\hline Education level 4 & -0.11 & 0.57 & -0.12 & 0.57 \\
\hline Technical & 0.51 & 0.39 & 0.51 & 0.39 \\
\hline Economic/administrative & 0.14 & 0.42 & 0.14 & 0.42 \\
\hline General & -0.11 & 0.58 & -0.10 & 0.58 \\
\hline No Children in household & -0.12 & 0.30 & -0.12 & 0.30 \\
\hline Married & -0.62 & 0.38 & -0.61 & 0.38 \\
\hline Civil Servant & -0.30 & 0.36 & -0.30 & 0.36 \\
\hline Part. in employee pension scheme & $-1.22^{* *}$ & 0.61 & $-1.22^{* *}$ & 0.61 \\
\hline Worker pays premium directly & $1.26^{* *}$ & 0.50 & $1.26^{* *}$ & 0.50 \\
\hline Employer attributes to premium & $0.89^{*}$ & 0.54 & $0.90^{*}$ & 0.54 \\
\hline Permanent job & $-2.16^{* *}$ & 0.39 & $-2.15^{* *}$ & 0.39 \\
\hline Part. in individual pension scheme & -0.02 & 0.38 & -0.01 & 0.38 \\
\hline 1995 & 0.25 & 0.47 & 0.24 & 0.47 \\
\hline 1996 & 0.01 & 0.48 & 0.00 & 0.48 \\
\hline 1997 & -0.23 & 0.49 & -0.24 & 0.49 \\
\hline 1998 & -0.31 & 0.49 & -0.31 & 0.49 \\
\hline 1999 & -0.45 & 0.50 & -0.46 & 0.50 \\
\hline 2000 & -0.55 & 0.52 & -0.55 & 0.52 \\
\hline Monthly earnings & 0.022 & 0.038 & 0.023 & 0.038 \\
\hline Other income/1000 & 0.46 & 0.31 & 0.47 & 0.31 \\
\hline Other income/1000 squared & -0.043 & 0.033 & -0.043 & 0.033 \\
\hline Total net weatlh/10000 & 0.0000044 & 0.0038 & & \\
\hline Total assets (incl. house)/10000 & & & 0.00010 & 0.0038 \\
\hline Debt (incl. mortgage)/10000 & & & -0.0030 & 0.014 \\
\hline Intercept & -735.6 & 472.9 & -738.9 & 473.3 \\
\hline
\end{tabular}


Table 6b: Results of multinomial logit model with assets (including house) and debt (including mortgage) The Job Exit Rate with Destination (Early) Retirement

\begin{tabular}{|c|c|c|c|c|}
\hline \multirow[b]{2}{*}{ Variable } & \multicolumn{2}{|l|}{ Net Wealth } & \multicolumn{2}{|c|}{$\begin{array}{l}\text { Assets and } \\
\text { Debts Separately }\end{array}$} \\
\hline & $\begin{array}{r}\text { Parameter } \\
\text { Estimate }\end{array}$ & $\begin{array}{r}\text { Standard } \\
\text { Error }\end{array}$ & $\begin{array}{r}\text { Parameter } \\
\text { Estimate }\end{array}$ & $\begin{array}{r}\text { Standard } \\
\text { Error }\end{array}$ \\
\hline Ln Age & 269.2 & 237.4 & 283.9 & 238.1 \\
\hline Ln Age Squared & -29.7 & 29.4 & -31.6 & 29.5 \\
\hline Education level 1 (lowest) & 0.97 & 0.59 & 0.74 & 0.60 \\
\hline Education level 2 & $1.21^{* *}$ & 0.49 & $1.01^{* *}$ & 0.49 \\
\hline Education level 3 & $1.16^{* *}$ & 0.45 & $0.98^{* *}$ & 0.46 \\
\hline Education level 4 & 0.49 & 0.46 & 0.39 & 0.46 \\
\hline Technical & -0.10 & 0.26 & -0.13 & 0.27 \\
\hline Economic/administrative & 0.14 & 0.29 & 0.20 & 0.29 \\
\hline General & 0.17 & 0.34 & 0.20 & 0.35 \\
\hline No Children in household & $0.51^{* *}$ & 0.23 & $0.53^{* *}$ & 0.23 \\
\hline Married & 0.13 & 0.29 & 0.22 & 0.29 \\
\hline Civil Servant & 0.22 & 0.22 & 0.21 & 0.22 \\
\hline Part. in employee pension scheme & -0.37 & 0.36 & -0.39 & 0.36 \\
\hline Worker pays premium directly & $0.86^{* *}$ & 0.40 & $0.84^{* *}$ & 0.41 \\
\hline Employer attributes to premium & -0.24 & 0.27 & -0.20 & 0.27 \\
\hline Permanent job & $1.10^{* *}$ & 0.55 & $1.14^{* *}$ & 0.55 \\
\hline Part. in individual pension scheme & -0.42 & 0.34 & -0.41 & 0.34 \\
\hline 1995 & $1.14^{* *}$ & 0.38 & 1.10 & 0.38 \\
\hline 1996 & 0.49 & 0.39 & 0.45 & 0.39 \\
\hline 1997 & $1.03^{* *}$ & 0.35 & $0.99^{* *}$ & 0.35 \\
\hline 1998 & 0.59 & 0.37 & 0.56 & 0.37 \\
\hline 1999 & 0.19 & 0.38 & 0.16 & 0.38 \\
\hline 2000 & 0.28 & 0.36 & 0.28 & 0.36 \\
\hline Monthly earnings & 0.024 & 0.026 & 0.027 & 0.025 \\
\hline Other income/1000 & -0.74 & 1.02 & -0.90 & 1.00 \\
\hline Other income/1000 squared & -0.63 & 0.91 & -0.57 & 0.88 \\
\hline Total net wealth/10000 & $0.00624^{* *}$ & 0.00310 & & \\
\hline Total assets (incl. house)/10000 & & & $0.00806^{* *}$ & 0.0031 \\
\hline Debt (incl. mortgage)/10000 & & & $-0.0283^{* *}$ & 0.012 \\
\hline Intercept & -607.6 & 479.3 & -636.2 & 480.8 \\
\hline $\begin{array}{l}* * \text { : significant at } 5 \text { per cent level } \\
* \text { : significant at } 10 \text { per cent level }\end{array}$ & & & & \\
\hline
\end{tabular}


Table 7: Elasticities of exit and staying on probabilities with respect to various measures of wealth, assets, and debt

\begin{tabular}{|c|c|c|c|}
\hline $\begin{array}{l}\text { Elasticity } \\
\text { with respect to: }\end{array}$ & $\begin{array}{l}\text { Sample average } \\
\text { for all variables }\end{array}$ & $\begin{array}{l}\text { Median for } \\
\text { variable that } \\
\text { elasticity is } \\
\text { calculated for }\end{array}$ & $\begin{array}{r}\text { Evaluated } \\
\text { at age } 60, \\
\text { sample average } \\
\text { other variables }\end{array}$ \\
\hline \multicolumn{4}{|l|}{ Net liquid wealth } \\
\hline Exit to retirement & $\begin{array}{r}0.11^{* *} \\
(0.04)\end{array}$ & $\begin{array}{r}0.049^{* *} \\
(0.019)\end{array}$ & $\begin{array}{r}0.11^{* *} \\
(0.04)\end{array}$ \\
\hline Exit to unemp./disab. & $\begin{array}{r}0.00077 \\
(0.058)\end{array}$ & $\begin{array}{r}0.00035 \\
(0.026)\end{array}$ & $\begin{array}{r}-0.0020 \\
(0.06)\end{array}$ \\
\hline Staying-on prob. & $\begin{array}{r}-0.000058 \\
(0.0006)\end{array}$ & $\begin{array}{r}-0.00023 \\
(0.00027)\end{array}$ & $\begin{array}{r}-0.0028 \\
(0.010)\end{array}$ \\
\hline \multicolumn{4}{|l|}{ Net wealth (liquid and ill.) } \\
\hline Exit to retirement & $\begin{array}{r}0.18^{* *} \\
(0.09)\end{array}$ & $\begin{array}{r}0.20^{* *} \\
(0.10)\end{array}$ & $\begin{array}{r}0.17^{* *} \\
(0.08)\end{array}$ \\
\hline Exit to unemp./disab. & $\begin{array}{r}0.000046 \\
(0.11)\end{array}$ & $\begin{array}{r}0.000050 \\
(0.12)\end{array}$ & $\begin{array}{r}-0.0042 \\
(0.11)\end{array}$ \\
\hline Staying-on prob. & $\begin{array}{r}-0.000077 \\
(0.0011)\end{array}$ & $\begin{array}{r}-0.000091 \\
(0.0012)\end{array}$ & $\begin{array}{l}-0.0043 \\
(0.015)\end{array}$ \\
\hline \multicolumn{4}{|l|}{ Total assets (liq. and ill.) } \\
\hline Exit to retirement & $\begin{array}{r}0.32^{* *} \\
(0.12)\end{array}$ & & $\begin{array}{r}0.30^{* *} \\
(0.12)\end{array}$ \\
\hline Exit to unemp./disab. & $\begin{array}{r}0.039 \\
(0.15)\end{array}$ & & $\begin{array}{r}-0.0050 \\
(0.15)\end{array}$ \\
\hline Staying-on prob. & $\begin{array}{r}-0.0020 \\
(0.0015) \\
\end{array}$ & & $\begin{array}{l}-0.0091 \\
(0.030)\end{array}$ \\
\hline \multicolumn{4}{|l|}{ Total debt (incl. mortgage) } \\
\hline Exit to retirement & $\begin{array}{r}-0.31^{* *} \\
(0.14)\end{array}$ & & $\begin{array}{r}-0.30^{* *} \\
(0.13)\end{array}$ \\
\hline Exit to unemp./disab. & $\begin{array}{r}-0.033 \\
(0.16)\end{array}$ & & $\begin{array}{r}-0.024 \\
(0.16)\end{array}$ \\
\hline Staying-on prob. & $\begin{array}{r}0.00048 \\
(0.0016)\end{array}$ & & $\begin{array}{r}0.0092 \\
(0.030)\end{array}$ \\
\hline $\begin{array}{l}* * \text { : significant at } 5 \text { per cer } \\
* \text { : significant at } 10 \text { per cer }\end{array}$ & & & \\
\hline
\end{tabular}




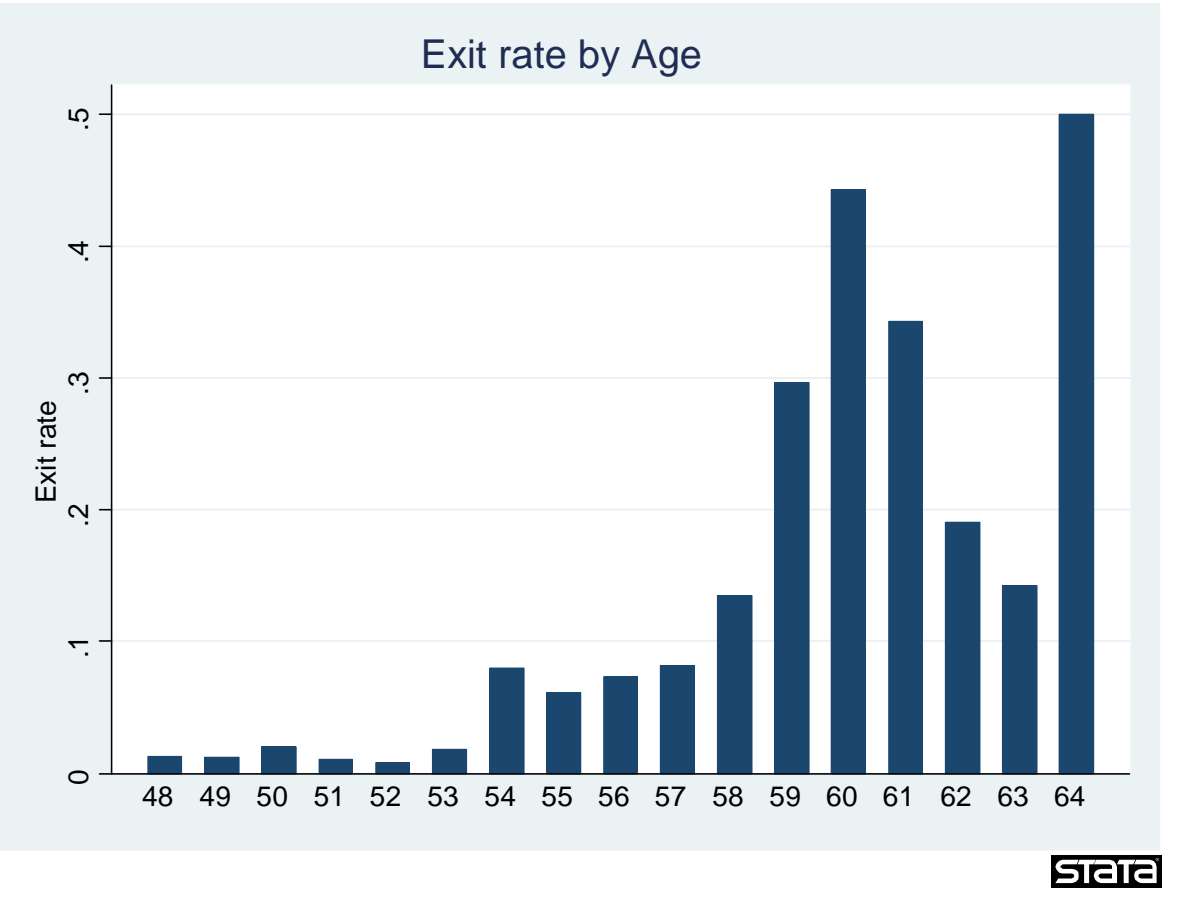

Figure 1: Exit rate by age 


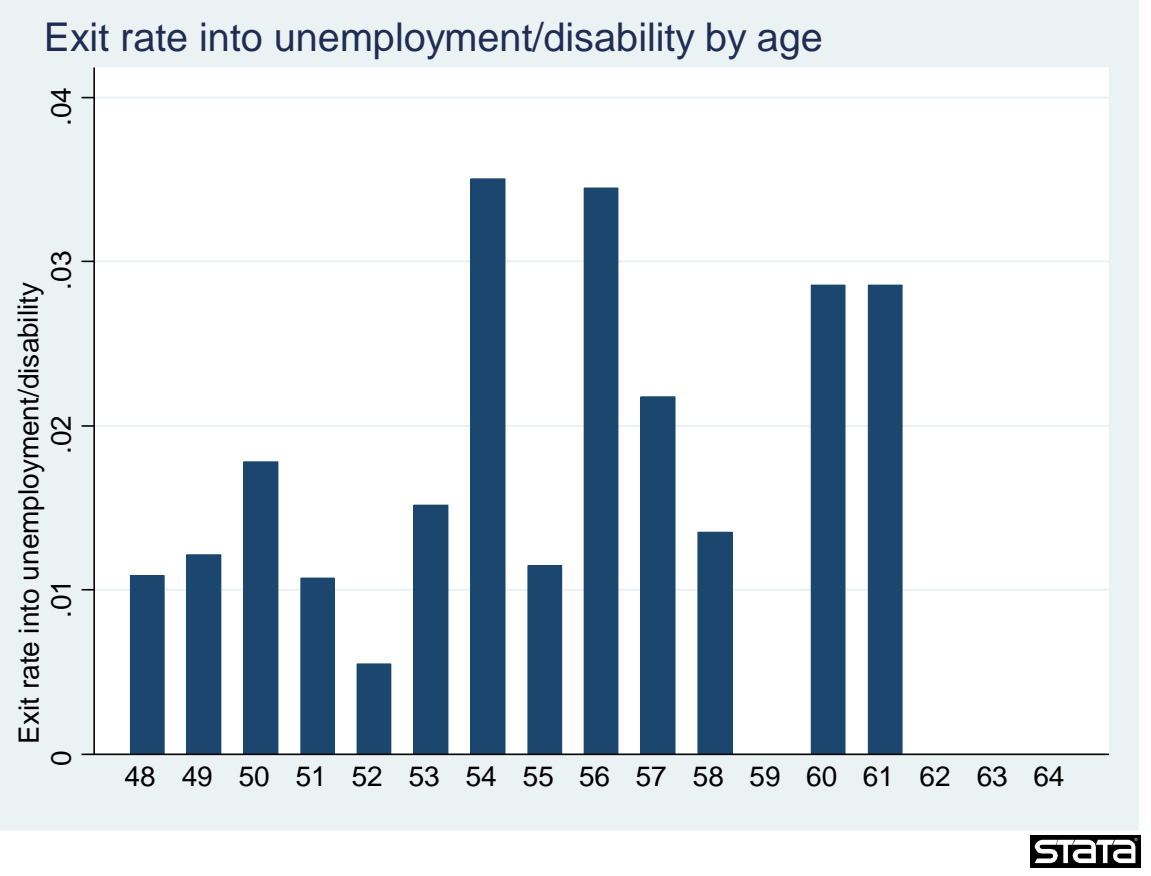

Figure 2: Exit rate into unemployment/disability by age 


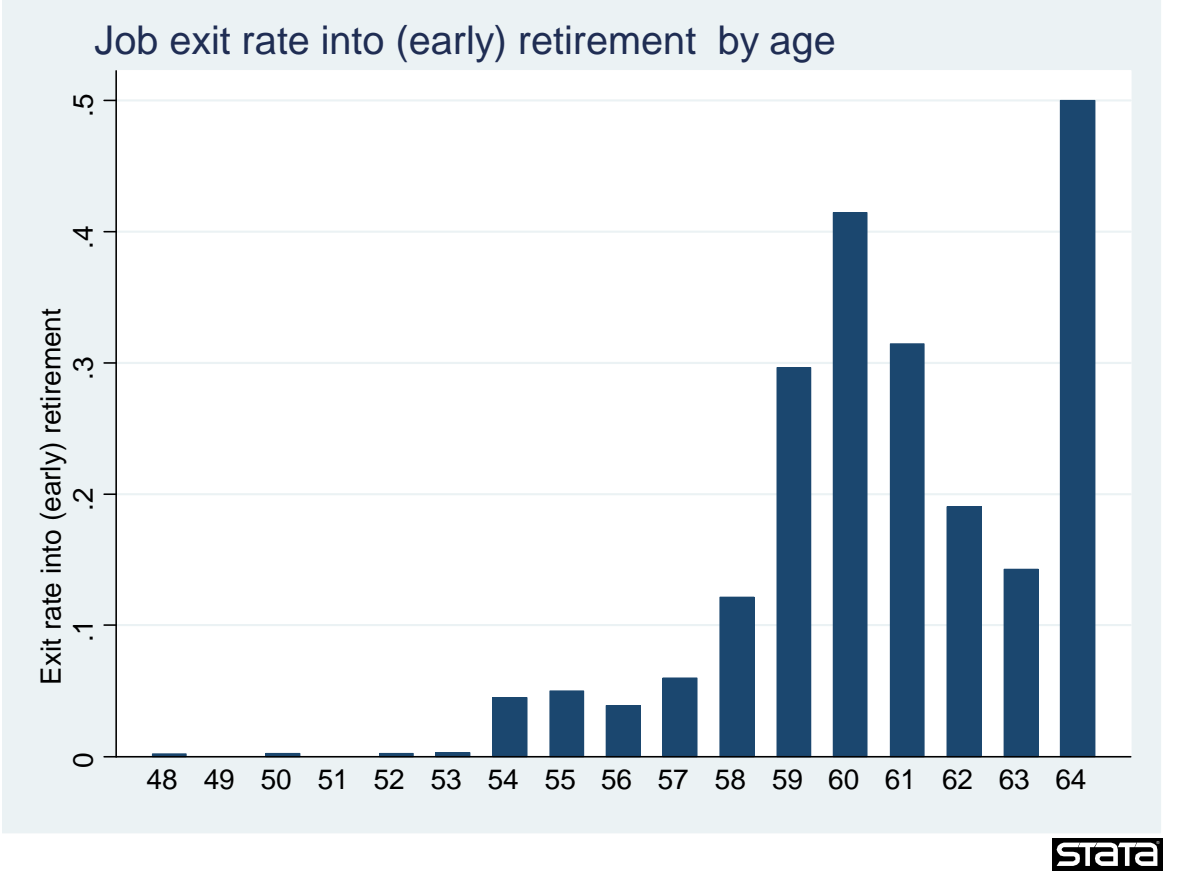

Figure 3: Exit rate into early retirement by age 


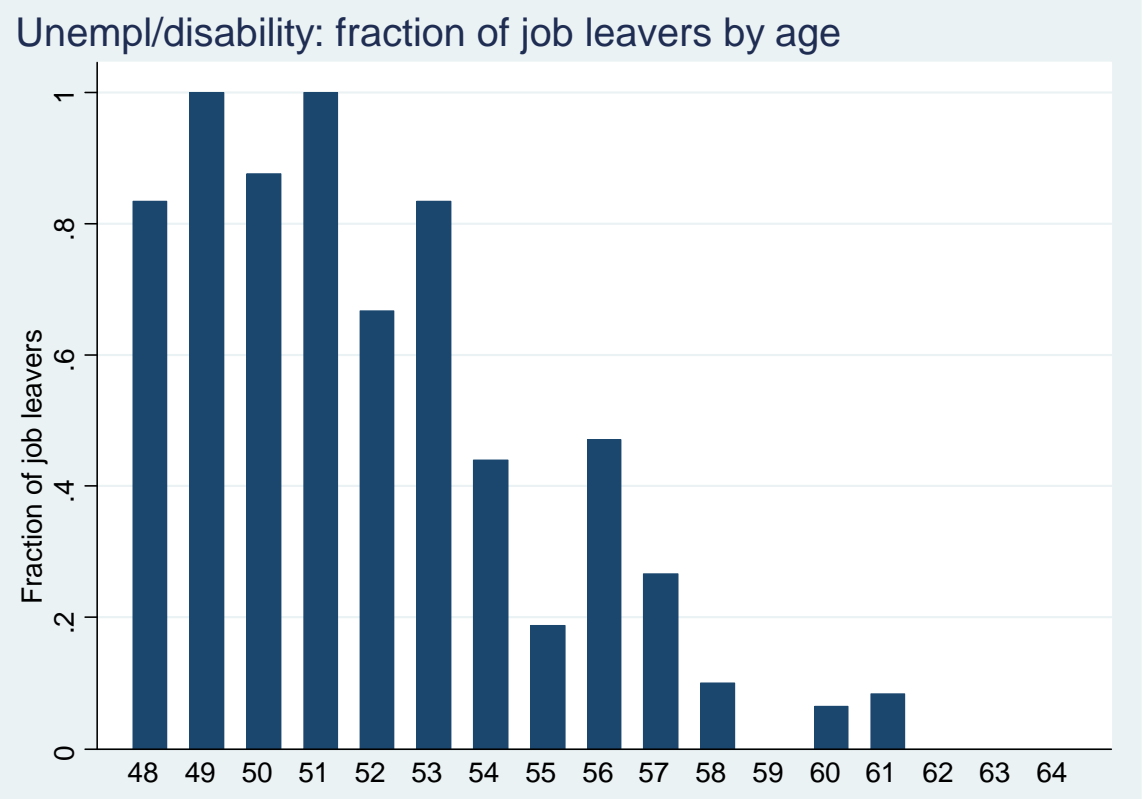

ETIO

Figure 4: Fraction of job leavers exiting by unemp/disability by age

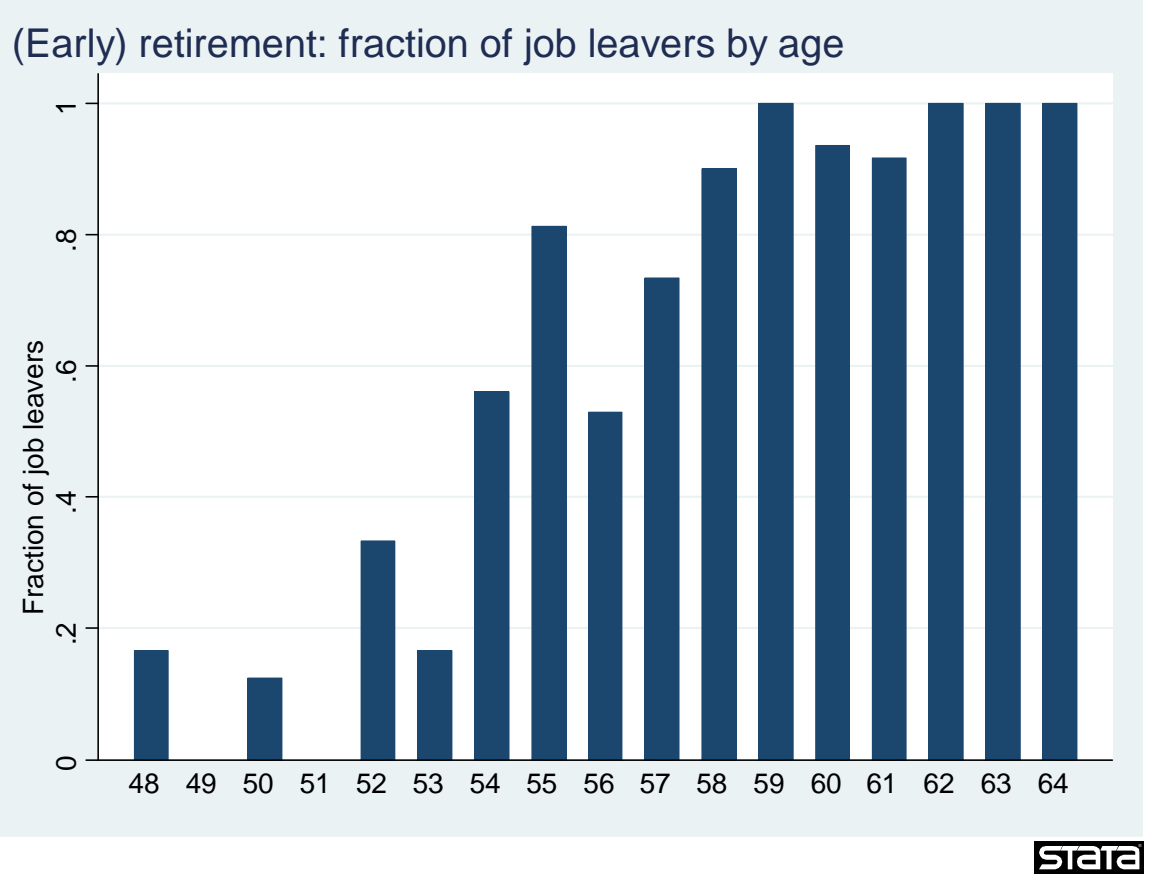

Figure 5: Fraction of job leavers exiting by (early) retirement by age 


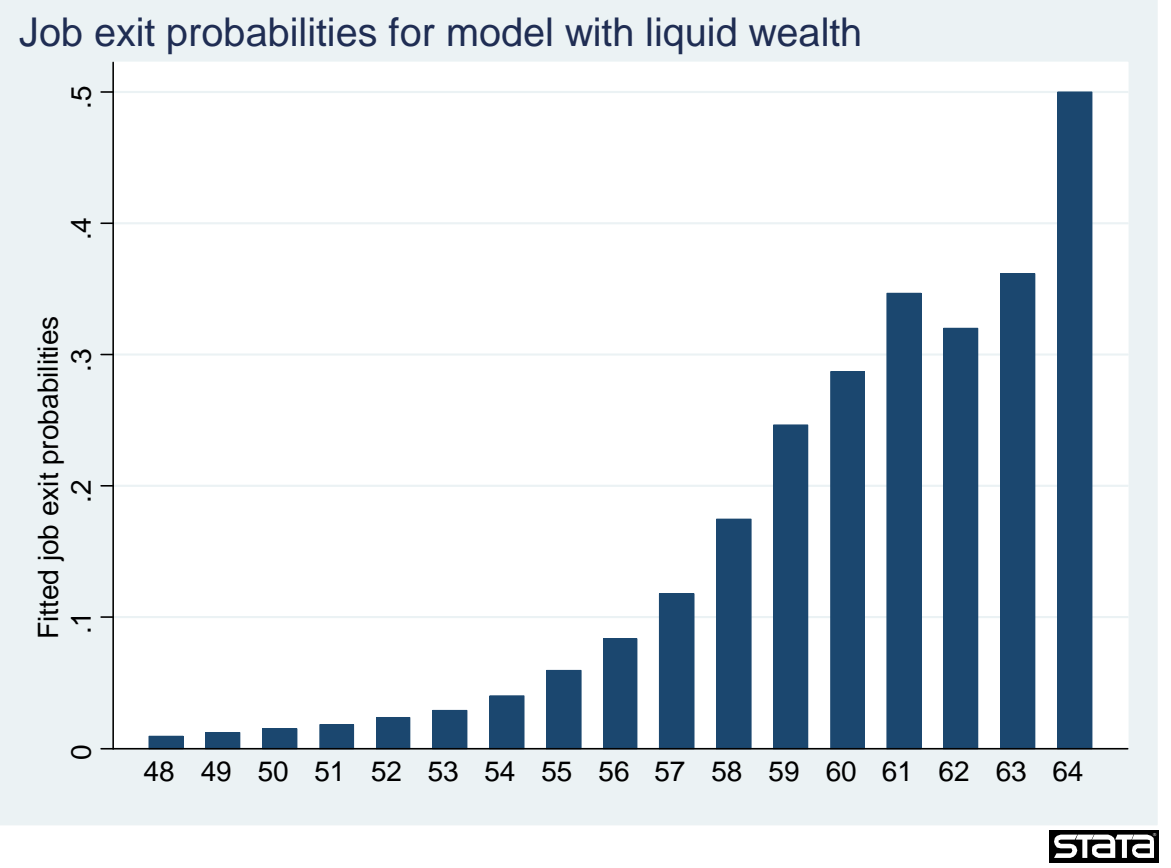

Figure 6: Mean of fitted job exit probabilities 


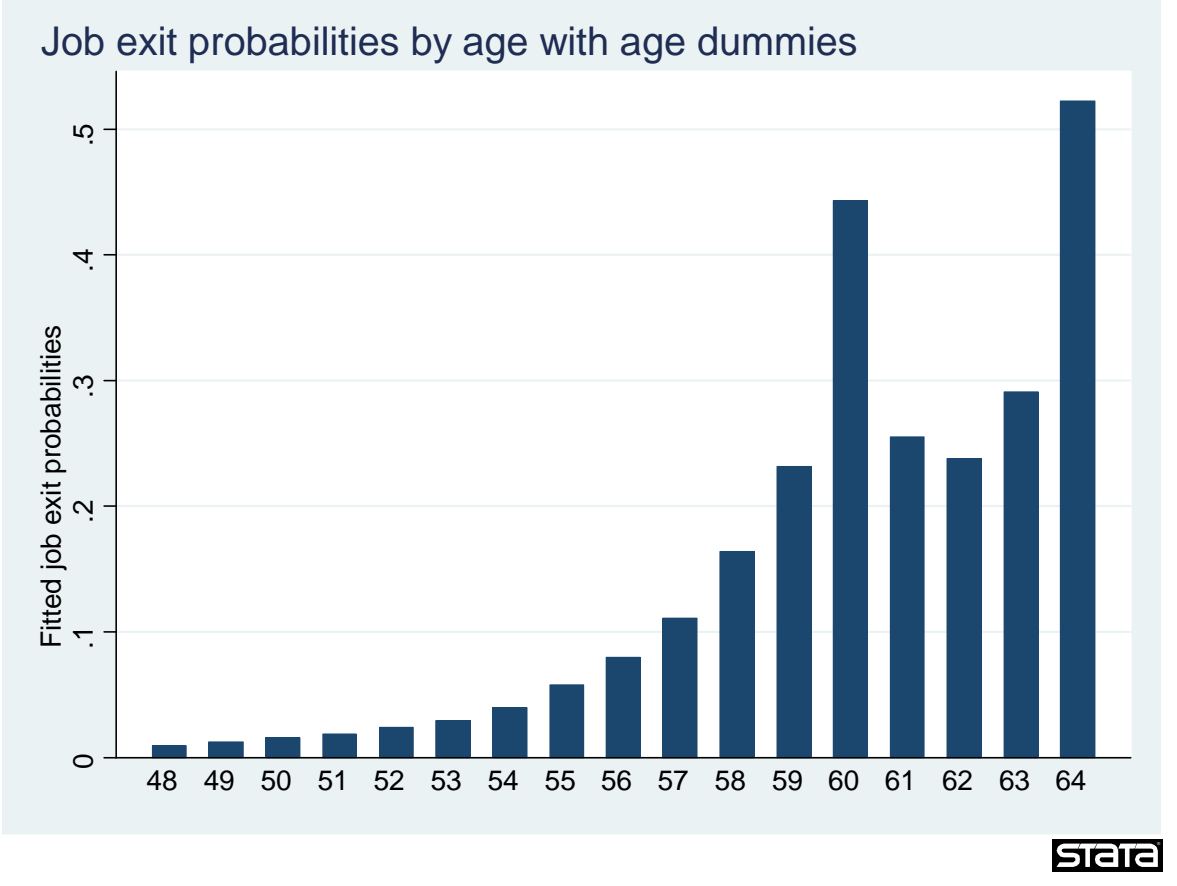

Figure 7: Fitted job exit probabilites: specification extended with age dummies 